\title{
"El clima de la clase": salud mental escolar en la España del desarrollismo
}

\author{
('Classroom climate': student mental health during \\ the Spanish developmentalist period)
}

\author{
Aida TERRÓN BAÑUELOS \\ Universidad de Oviedo \\ InTA HURTADO GARCÍA \\ Universidad CEU Cardenal Herrera
}

RESUMEN: Este artículo intenta identificar las distintas concepciones de la salud mental escolar que se dieron a partir de los años cincuenta, articuladoras, en buena medida, del modelo de escuela que trató de configurarse tras la II Guerra Mundial. A través de diversos textos, da cuenta de los enfoques que pretendieron orientar el perfil de la dinámica escolar desde los requisitos de la salud mental. Y centra, concretamente, el reflejo de esta situación en España, apuntando las influencias que llegaron a tener cierta viabilidad y calado. Nos centraremos en los Cuadernos para la educación en salud mental en tanto que reflejo de los debates en torno a la (re)organización de los campos de saber en salud mental y en educación, con efectos sobre la figura del maestro y del resto de profesionales que pasarán a formar parte de lo escolar.

PALABRAS CLAVE: salud mental; escuela; servicios psicológicos escolares; desarrollismo; clima de la clase.

ABSTRACT: This article examines the different conceptions of student mental health that emerged in the aftermath of World War II, and the model of school pursued from the 1950s onwards. The study chronicles the different attempts to refocus the dynamics of classroom instruction based on mental health considerations, looking in particular at their impact and legacy in Spain. The analysis focuses on the Cuadernos para la educación en salud mental as a reflection of contemporary debates around the (re)organisation of areas of knowledge in relation to mental health and education and the impact of this remodelling on the figure of the teacher and the inclusion of new professional roles within the education system.

KEYWORDS: mental health; school; student psychology services; developmentalism; classroom climate. 
Este trabajo se originó de manera imprevista hace un par de años mientras localizábamos fuentes bibliográficas que documentasen una investigación sobre la divulgación sanitaria en España, particularmente en su dimensión escolar, que nos ocupaba desde hacía tiempo. Nos interesábamos entonces por la situación de la educación sexual de los niños y niñas durante la fase de la Transición democrática, un asunto en el que encajaban sorprendentemente bien diversos títulos que íbamos localizando (Infancia y sexualidad, Adolescencia y sexualidad, Sexo y sexualidad, Las enfermedades de transmisión sexual), los cuales, como más tarde supimos, formaban parte de los Cuadernos para la educación en salud mental (en adelante, CESM). Se trataba de una amplia colección compuesta por 50 pequeños folletos de una singular diversidad temática editados entre 1974 y 1979 por la Unidad de Educación en Salud Mental del Patronato Nacional de Asistencia Psiquiátrica (PANAP). La salud mental venía recibiendo atención por las Comisiones de Expertos de diversos organismos internacionales de educación y de salud -UNESCO y OMS, particularmente-, incluyéndola dentro de la esfera la educación sanitaria escolar. De ahí nuestro interés por esta singular fuente, procediendo inmediatamente a su localización, consulta sistemática y análisis de su contexto de gestación y enfoque.

Los escasos estudios que han reparado en esta colección provienen de investigadores del campo de la historia de la salud mental, ${ }^{1}$ considerándola un instrumento con fines divulgativos promovido por Adolfo Serigó Segarra, el entonces director del PANAP. Nuestro interés por esta fuente, explorada en su conjunto pero con particular atención en aquellos cuadernos del ámbito escolar, radica en la propia propuesta. Esta representa un intento de apertura a planteamientos y escenarios nuevos, configurándose como una síntesis de algunas de las tradiciones en salud mental que se van a concentrar en los años setenta. Este abanico, deudor de un nuevo modo de comprensión de la salud mental reflejado en temáticas y enfoques propios de una sociedad en transformación, va a tener en España un alcance muy limitado en su difusión y con escaso calado educativo.

En este artículo pretendemos analizar, mediante diversas fuentes, las concepciones y articulaciones de la salud mental escolar que se dieron a partir de los años cincuenta y que nos permiten contextualizar los CESM desde la perspectiva de la (re)organización de campos de saber, pero también de posicionamientos epistémicos e incluso políticos. Para hacerlo, nos centraremos en textos y enfoques que pretenden movilizar el perfil de la dinámica escolar desde los requisitos de la salud (o higiene) mental; a través de ellos trataremos de identificar esquemáticamente las propuestas realizadas por los especialistas

\footnotetext{
${ }^{1}$ Ver: Enric J. Novella Gaya, "La psiquiatría franquista y la educación para la salud mental", en Educación, comunicación y salud, coords. Josep M. Comelles y Enrique Perdiguero-Gil (Tarragona: Publicacions URV, 2017), 81-103. Disponible en http://libres.urv.cat/index.php/purv/catalog/download/264/299/653-1?inline=1; Enric J. Novella Gaya, "Los límites de la tecnocracia: La modernización autoritaria de la asistencia psiquiátrica en la España del segundo franquismo", Dynamis: Acta Hispanica Ad Medicinae Scientiarumque Historiam Illustrandam 39, no. 1 (2019): 73-97; David Simón Lorda, "El Patronato Nacional de Asistencia Psiquiátrica (PANAP) y sus contradicciones: entre el enfoque psicosocial y el modelo manicomial", en Psiquiatría y antipsiquiatría en el segundo franquismo y la Transición, ed. Rafael Huertas (Madrid, España: Catarata, 2017), 15-46; David Simón Lorda, "Atención psiquiátrica. salud mental y salud pública en el tardofranquismo", en Genealogías de la reforma sanitaria en España, eds. José Martínez Pérez y Enrique Perdiguero Gil (Madrid, España: Catarata, 2020), 127-154.
} 
de los organismos supranacionales (básicamente la UNESCO) y, desde una perspectiva bien distinta, las conformadas desde la base por los maestros y maestras del Movimiento Freinet. En un segundo momento, mostraremos el reflejo de esta situación en nuestro país a través de aquellos autores y enfoques que penetraron en el discurso para, en un tercer y último apartado, ver cómo todo ello se articuló en la propuesta desplegada en los CESM.

El análisis nos va a permitir identificar el marco interpretativo y de acción desde el que se estaba pensando la escuela en la Europa que siguió a la II Guerra Mundial, y se conformó a lo largo de las décadas 50-70, qué cultura de la salud se estaba manejando en ella y sus implicaciones a efectos de su organización y función social. Un nuevo modelo que va a ser enunciado entre adhesiones, disensos y debates en los que se van a ir perfilando el campo de saberes de la salud mental escolar, y en los se van a disputar las posiciones y competencias del maestro y del resto de profesionales que entran a formar parte de lo escolar.

A lo largo del trabajo se desliza una idea central cuya explicitación inicial facilitará su lectura. Y es la de que el conocimiento sobre salud mental que necesitan manejar los educadores -maestros, principalmente - tenía una proyección directa sobre "el clima de la clase", elemento condicionante, e incluso determinante, para articular una "educación integral" del alumno, que solo sería posible si el maestro, artífice del mismo, era capaz de manejar las dinámicas grupales, las relaciones jerárquicas en el aula, los conflictos emocionales, las reacciones de rechazo o frustración, etc. La crítica a una escuela que, reproduciendo el inhóspito medio social en que está inserta, se muestra incapaz de acoger y dar seguridad a su alumnado, fue sistemática en Freinet pero permea también muchas de las manifestaciones de las que aquí nos hacemos eco.

\section{De la feliz adaptación del niño a la vida escolar a la formalización de los servicios psicológicos escolares}

Los años setenta, década de publicación de los CESM, van a ser escenario de un impulso para la modernización de la educación. Una actividad intensiva de expertos a nivel internacional busca actualizar una agenda educativa acorde a los nuevos tiempos y, aparejado a ello, definir los grupos profesionales intervinientes delimitando sus respectivos campos de acción. Los discursos renovadores que se van a desplegar son deudores de aquellos que venían conformándose desde la década de los cincuenta en distintas conferencias y reuniones de organismos como la UNESCO y la OMS, inexcusables en un momento atravesado por improntas sociales como la posguerra, la industrialización, la democracia, la emigración de masas, y la declaración de los derechos a la educación y a la salud, entre otros elementos. En esta coyuntura de cambio, de turbulencias y exigencias, los diferentes gremios profesionales y científicos van a tratar de afianzar su posición en el terreno escolar. No con el mismo optimismo de los reformistas del siglo XIX, pero todavía considerando la escuela como uno de los medios más fértiles de que dispone la sociedad para modelar las futuras generaciones. ${ }^{2}$

\footnotetext{
${ }^{2}$ Williams Douglas Wall, Educación y Salud Mental (Madrid: Aguilar, 1963 [1955]), 8. Disponible en https:// unesdoc.unesco.org/ark:/48223/pf0000133608.
} 


\section{La Conferencia: la educación y la salud mental de los niños en Europa (1952)}

Proclamada en 1948, la Declaración Universal de Derechos Humanos incluía el derecho a una educación, gratuita y obligatoria, que tenga por objeto "el pleno desarrollo de la personalidad humana" (art 26). ${ }^{3}$ A la altura de 1952, la UNESCO proponía en su emblemática publicación El derecho a la educación, ${ }^{4}$ superar el reduccionismo de tal derecho a los aspectos instructores y alfabetizadores a los que, de facto, se había limitado. La educación, ineluctablemente asociada a la salud mental de la población —particularmente la infantil-, y a "la evolución del conjunto de la humanidad" tenía que abordarse con una perspectiva más psicológica, que atendiese, como quería Piaget, ${ }^{6}$ al "pleno desarrollo de la personalidad humana". ${ }^{7}$ Ese mismo año, numerosos especialistas procedentes del campo de la psicología escolar, la psicopedagogía o pedagogía psicológica, el psicoanálisis, la administración escolar etc., tratarán ampliamente el asunto en el marco de la "Conferencia regional sobre la educación y la salud mental de los niños en Europa", celebrada en el Museo Pedagógico de París del 27 de noviembre al 17 de diciembre de 1952. Su organización, a cargo de la UNESCO, va a contar con la colaboración de la ONU (División de cuestiones sociales y UNICEF), la OMS y diversas organizaciones internacionales competentes, oficiales y no gubernamentales.

Los trabajos presentados en la Conferencia, ${ }^{8}$ mayormente por ingleses, franceses y belgas, revelaban avances de la investigación en un amplio abanico de asuntos. Desde los enfoques predominantes de la psicología evolutiva y del desarrollo y de la psicología escolar, entre otros, los asistentes van a tratar de precisar "la influencia de los métodos, de la organización y del medio escolar sobre la formación de la personalidad de los alumnos en Europa, considerando el caso de niños normales situados en condiciones normales, puesto que son estos niños los que forman la inmensa mayoría de las generaciones venideras", marginando en esta ocasión una mirada más patológica. ${ }^{9}$ Una de las principales características de este trabajo conjunto, reside en la estrecha conexión que cada uno de los expertos establece entre las preocupaciones educativas y las recientes investigaciones

\footnotetext{
${ }^{3}$ Disponible en: https://www.ohchr.org/EN/UDHR/Documents/UDHR_Translations/spn.pdf

${ }^{4}$ UNESCO, El derecho a la educación (París: UNESCO, 1952).

${ }^{5}$ Ibídem, 2.

6 "El derecho a la educación es el derecho del individuo a desarrollarse normalmente, en función de las posibilidades de que dispone y la obligación para la sociedad de transformar esas posibilidades en realizaciones efectivas y útiles". Jean Piaget, Le droit à l'éducation dans le monde actual, Colecc. Droites de l'homme, 1 (París: UNESCO, 1949), 12. Disponible en: https://unesdoc.unesco.org/ark:/48223/pf0000139216.

${ }^{7}$ En las obras consultadas en idiomas extranjeros, las citas directas e indirectas son traducciones de las autoras. ${ }^{8}$ Los materiales sobre los que trabajaron los participantes fueron preparados por 15 especialistas del campo reunidos a lo largo del año, y posteriormente enviados a destinatarios de 27 países. Durante tres semanas, 30 especialistas (administradores de la enseñanza, educadores, psicólogos, psiquiatras y asistentes sociales) procedentes de 13 países europeos (y otros de América Latina, India y Estados Unidos) estudiaron los documentos. Los asistentes-expertos, más de 60, representaban a Estados miembro de 19 países europeos, expertos independientes y representantes de ONGs competentes en la materia. La Biblioteca de la UNESCO conserva los documentos de la Conferencia alojados en 121 archivos en línea. Williams Douglas Wall, Educación y Salud Mental.

${ }^{9}$ Ibídem, 401.
} 
de la psicología infantil, sobre todo en el terreno de la psicología afectiva. Podría decirse, por un lado, que esta obra constituye un estudio de la psicología aplicada a la educación y, por otro, un inventario de las ideas pedagógicas nuevas y de reformas en curso, juzgadas a la luz de dicha psicología. De esta forma, no solo se llega a establecer firmemente la función social de la escuela y del maestro, sino también la importancia de la psicología en su formación y en la definición de métodos pedagógicos sanos. Se está conformando el nuevo campo de la psicología escolar.

Si se mira con perspectiva, se observa el empeño de los organismos internacionales por extender su intervención de manera coordinada sobre las diferentes esferas que atañen a la educación durante esos años. Solo dos años después de la "Conferencia sobre salud mental y educación" (1952), se crea el "Comité Consultivo Internacional sobre Programas y Planes de estudios" por la UNESCO. Su misión era la de promover reformas curriculares de fondo, aplicables particularmente a aquellos países que tras la II Guerra Mundial seguían anclados en los modelos tradicionales. Abundando en ello, cinco años después el Comité emite el informe Planes y Programas de Estudio: análisis y revisión, orientando los procedimientos metodológicos que debían guiar los procesos de reforma organizativa y curricular nacionales ${ }^{10}$ e incorporando, como elementos de mejora, los apoyos de otras ciencias. Una de ellas es la Psicología, cuya orientación "escolar" tiene, en la Conferencia que analizamos, una sanción definitiva tras años de orbitar en el movimiento de la salud mental y el modelo clínico de intervención —las Child Guidance Clinics-. De hecho, en el marco de la Conferencia surgió ya a iniciativa del Instituto para la Educación de la UNESCO — sito en Hamburgo—, un grupo de trabajo sobre "Servicios psicológicos para las escuelas y demás centros de enseñanza"11 que organizaría a su vez, dos años después, otra Conferencia monográfica sobre "Servicios Psicológicos Escolares". ${ }^{12}$ Su objetivo era que grupos de expertos avanzasen sobre los principios, los objetivos y las estructuras mentales de los servicios psicológicos que venían siendo creados para las escuelas y otros establecimientos de enseñanza. A tal fin se recopiló información de las autoridades de múltiples países que permitió un sistemático estudio comparado sobre sus diferentes situaciones en Europa y USA, pronunciándose expresamente la Conferencia por adoptar el francés como modelo.

Tras este pequeño excurso, y volviendo a 1952, vale la pena destacar dos intervenciones representativas presentadas a la Conferencia de París acerca de este asunto. Una de ellas será suscrita por René Zazzo (1952), representando justamente la posición france-

\footnotetext{
${ }^{10}$ Ver: Aida Terrón, "La educación sanitaria escolar, matriz generadora de las materias transversales del currículum (1960-1980)", en Modernización educativa y socialización política. Contenidos curriculares y manuales escolares en España durante el tardofranquismo y la transición democrática, coord. Manuel Ferraz, (Madrid, Morata, 2019), 280-305.

${ }^{11}$ Para un primer estudio sobre su diversidad ver: Les psychologues scolaires, ํํ 104 (Ginebra y París: BIEUNESCO, 1948).

${ }^{12}$ Ver: William Douglas Wall, La Psycologie au service de l'ecole (París: Bourrelier, 1958). Disponible en: https:// unesdoc.unesco.org/ark:/48223/pf0000131606.
} 
sa. ${ }^{13}$ Zazzo era en ese momento director del Laboratorio de Psicología del Niño, dependiente de la Escuela de Altos Estudios de París, creado y dirigido por Henry Wallon desde 1927 como continuación de un previo Laboratorio Psicopedagógico. El empeño en organizar unos servicios psicopedagógicos insertos y vinculados a la orientación de la labor de escuela pública francesa había llevado a Wallon a incluirlos y formalizarlos mediante la ley Langevin-Wallon de reforma de la educación francesa en 1947. Es esa orientación, justamente, la que Zazzo precisa en su intervención, como respuesta a "la necesidad general de una mejor adaptación del alumno a la escuela y la apropiación de la vida escolar por los intereses del niño en un mundo cuyos patrones sociales son cada vez más complejos, y con un universo profesional y cultural cada vez más rico y diversificado".

Por su parte, en el "Memorando de Los Servicios Psicológicos en Europa", la Sociedad Británica de Psicología ${ }^{14}$ presenta también unas recomendaciones relativas a la implantación de servicios psicológicos escolares. Con un claro propósito de delimitar profesionalmente su acción en el ámbito de la salud escolar, sostiene que los psicólogos, a diferencia de la exclusividad diagnóstica de los médicos, aportan la prevención y la orientación, además del tratamiento de los inadaptados y de otras dificultades educativas. Recomienda una "cercana armonía" al resto de profesionales del servicio —compuesto por médicos, educadores y trabajadores sociales-, a quienes se les exige una formación psicológica añadida, privilegiando de este modo el filtro psicológico para la atención de la salud escolar en la disputa por el privilegio epistémico y pragmático. La identidad profesional del psicólogo escolar va a ir fraguando su lugar en la trama escolar, incardinándose en una estructura y definiendo sus funciones, así como proponiendo un marco de análisis de la realidad escolar que va a ser desarrollado en publicaciones como la que analizamos a continuación.

\section{El documento: Educación y salud mental (1955)}

De la Conferencia mencionada surgieron distintos materiales publicados por sus autores. Nos detendremos en un texto de conjunto, Educación y Salud mental, de William Douglas Wall, ${ }^{15}$ publicado un año después de la Conferencia y elaborado a partir de los documentos presentados en ella, a modo de "fruto de la colaboración internacional entre hombres de ciencia de muchos países, especialistas en diversas materias". ${ }^{16}$ Su relevancia se deriva de que no se limita a ser un simple informe de los trabajos de la Conferencia, sino que supone una guía de actuación para autoridades educativas y expertos, con una amplia y sistemática bibliografía que permite conocer la orientación y el estado de la investigación en aquel momento.

\footnotetext{
${ }^{13}$ René Zazzo, "Report on school Psychology", en Conference on Education and the Mental Health of Children in Europe (París: UNESCO, 1952).

${ }^{14}$ The British Psychological Society, Commitee of Professional Psychologists (Mental Health), "Memorandum on the schools' psychological services in Europe", en ibídem.

${ }^{15}$ Wall era profesor de Psicología de la Educación y jefe del Departamento de desarrollo del niño y psicología de la educación del Instituto de Educación de la universidad de Londres. Wall hará en 1975 una actualización de esta obra, en dos volúmenes, adaptado a la situación en dicha fecha (Constructive education for children y Constructive Education for Adolescents).

${ }^{16}$ Wall, Educación y Salud Mental, 404.
} 
Jean Piaget, autor del prefacio, comienza destacando la idea que centra la Conferencia y sus organizadores; esto es, perseguir el desarrollo armónico del individuo tanto intelectual y afectiva como socialmente a partir de la revisión de los métodos de educación desde el filtro de los avances de la psicología infantil. ${ }^{17}$ Con ello, demarca su objetivo y, a su vez, anticipa el advenimiento de una cultura escolar basada en la influencia de las relaciones interpersonales y en la intervención sobre los individuos. Las dos guerras mundiales son un imperativo para el cambio, puesto que dejaban al descubierto el fracaso del modelo de instrucción escolar anterior y la amenaza del derrumbamiento de los valores colectivos. No en vano, el primer capítulo de la obra se titula: "La salud mental y las tensiones internacionales". En este escenario se establece el nuevo marco del papel de la salud mental en la educación, a la vez que se contribuye a estrechar un nexo de unión más eficaz entre las ciencias modernas de la psicología del niño y la pedagógica, por una parte, y la actividad de las escuelas europeas, por otra.

Una vez abordadas las consecuencias psicológicas de los conflictos internacionales y establecidos los bastiones involucrados en procurar individuos sanos y adaptados a la sociedad (hogar familiar, escuela y servicios generales), los próximos seis capítulos se centran en los grupos de edad/ciclo de la instrucción escolar —obligatoria desde los cinco o seis a los catorce o quince años de manera generalizada - de los que la Conferencia se ocupa. Para cada grupo se describen las características psicológicas y las funciones específicas de la escuela. La educación primaria y la segunda enseñanza, además, merecen respectivamente un capítulo sobre "algunos" de sus problemas. Entre los primeros, los problemas de orden psicológico y académico derivados de la interdependencia de la vida intelectual y afectiva, de la entrada en la escuela, o de las consecuencias de forzar los ritmos de aprendizaje. También aquellos relacionados con el desarrollo de la inteligencia, las capacidades mal explotadas, el retraso escolar, ${ }^{18}$ o los preocupantes casos límite (niños obtusos). ${ }^{19}$ En la enseñanza secundaria se ocupan de los efectos negativos de la multiplicidad de maestros especializados por materias, la fatiga, el exceso de deberes escolares, la competitividad, los castigos corporales, la educación sexual o la coeducación, particularizando en un epígrafe la educación de las muchachas.

Hay un interés manifiesto en que la educación desempeñe una misión más allá de "la de evitar a los niños dificultades inútiles". ${ }^{20}$ Tiene un papel constructivo en el desarrollo "mental y afectivo" de los escolares y por extensión, de la sociedad. Por ello va a haber un énfasis en elementos tan capitales, entonces y ahora, como procurar la adaptación de los objetivos educativos al estadio de crecimiento, o cuestionar aquella educación que tensiona la relación con los niños y la uniformización de las clases sin atender a las necesidades

\footnotetext{
17 Ibídem, IX.

${ }^{18}$ En el índice de materias, el término retraso mental se establece como sinónimo de atraso mental e insuficiencia mental. El atraso mental a su vez se relaciona con la inadaptación escolar.

${ }^{19}$ Un tipo de atraso escolar se relaciona con la brusquedad con la que se somete a los niños a un aprendizaje formal 0 a reglas arbitrarias y, sobre todo, con cómo, al querer enseñarles demasiado pronto a leer y a contar, se multiplican en la enseñanza primaria los casos de retraso escolar.

${ }^{20}$ William Douglas Wall, Educación y Salud Mental, 147.
} 
y posibilidades de cada uno. Pero tras los problemas señalados, también se puede entrever una crítica a los enseñantes progresistas y a su concepción de que la autodisciplina y la observación de las reglas indispensables a la vida en sociedad son fruto del libre ejercicio de las tendencias naturales de los niños y de los adultos que forman la colectividad. Se afirma que "no puede asegurarse [un] desarrollo mental afectivo y satisfactorio ni por medio de una libertad rayana con la licencia ni por una disciplina rígida y fría, unida a unas exigencias imposibles". ${ }^{21}$ Se considera que estas pedagogías descuidan principios fundamentales para un desarrollo mentalmente sano, como la seguridad que emana de los límites impuestos por una disciplina benévola y la restricciones que constituyen la condición preliminar indispensable de toda vida en sociedad.

Una vez expuestas las características y necesidades de aquel alumnado "normal", el capítulo noveno se ocupa de los problemas de los "grupos especiales". Los también llamados "atípicos", se clasifican y describen en apartados tales como: la insuficiencia mental, los niños delicados y deficientes físicos o los niños inadaptados. Los niños inadaptados son los que plantean más lagunas a la hora de determinar su "naturaleza" porque, según las encuestas efectuadas en las escuelas, son "niños física e intelectualmente normales". En este difuso umbral entre la normalidad y la anormalidad, se apunta a factores psicosociales pero que no van más allá de la impronta que dejan en los niños determinados sucesos y relaciones en el ámbito familiar. Tratando de explicar la paradoja de la inadaptación, esta se atribuye al "desequilibrio entre los recursos (nótese, psicológicos) de un individuo y las exigencias de la sociedad en que vive". ${ }^{22}$

Los factores socioculturales, aunque escasamente mencionados, no toman cuerpo ni penetran el análisis. Esta consideración laxa del "medio social" se utiliza únicamente para matizar las categorías psicológicas establecidas, pero no para cuestionar la propia constitución de las mismas en relación con el contexto. En el apéndice sobre la inteligencia, considerada hereditaria, reconocen que el medio también afecta a la misma. Así, reconocen que según se trate de familias con más o menos hijos, de una u otra clase social, de la Europa del Este o del Oeste, o de una u otra etnia, puede que haya algún tipo de inteligencia que no midan los test: aquella "que se expresa en la vida cotidiana, la vida escolar o la vida profesional". ${ }^{23}$ Con ello se reconoce un conocimiento etnográfico que ni epistémica ni metodológicamente está en condiciones de incorporar un paradigma que se establece desde "una concepción clausurada del ser" derivada de la naturalización de las características individuales ${ }^{24} \mathrm{y}$ al margen de su interacción con el medio sociocultural. De hecho, se introduce la diversidad cultural como obstáculo, como aquello con lo que la escuela ha de lidiar "en las culturas complejas y evolucionadas de Europa", ${ }^{25}$ a diferencia

\footnotetext{
${ }^{21}$ Ibídem, 88.

22 Ibídem, 286.

${ }^{23}$ Ibídem, 393.

${ }^{24}$ Ángel Martínez-Hernáez y Martín Correa-Urquiza, "Un saber menos dado: Nuevos posicionamientos en el campo de la salud mental colectiva", Salud Colectiva 13 (2017): 269.

${ }^{25}$ Lo hemos constatado en relación con la educación sexual escolar y con la educación para la salud y la vida familiar, temáticas "calientes" que presentaban importantes resistencias culturales. Muestra de ello son aquellas
} 
de otros tiempos en los que la misión educativa era más fácil, cuando "la enseñanza era privativa de un grupo limitado de niños elegidos según ciertos criterios particulares: la clase social, el nivel intelectual, las ideas religiosas o políticas". ${ }^{26}$

El capítulo décimo, "Salud mental y la enseñanza", es el único que amplía la perspectiva psicológica al introducir una radiografía socio-psicológica del magisterio primario. En él se incorporan datos y referencias sociológicas y se exponen las implicaciones que la formación, el estatus social y la personalidad del docente tienen en la enseñanza y el alumnado. La disposición del docente es analizada en tanto que se considera un elemento central como generador de la "atmósfera en la escuela"27 que el niño respira (el clima de la clase). Esta idea va a quedar arraigada en desarrollos posteriores, subsumiendo al propio docente y su actividad a la mirada y orientación psicológica. La supervisión y orientación de acciones y prácticas cotidianas escolares van marcando un cambio en la cultura institucional de la escuela, en la que, si se quiere "aportar verdaderamente una contribución positiva al feliz desarrollo de los niños y de los adolescentes, es preciso que [el docente] pueda recurrir a la suma de conocimientos y de técnicas acumulados desde hace un siglo por las investigaciones de psicología educativa y que cada día van enriqueciéndose"..$^{28} \mathrm{El}$ capítulo se cierra estableciendo las características y funciones de los servicios psicológicos escolares, compuestos por "un psicólogo escolar, una enfermera y, en muchos casos, un psiquiatra". ${ }^{29}$

El último capítulo recoge "Algunos de los problemas por resolver". En él se nos devuelve al prólogo en tanto que se reconoce la existencia de un "conocimiento bastante exacto del desarrollo del niño", ${ }^{30}$ un tema en el que todavía serían necesarias más investigaciones que guíen las intervenciones con las que mejorar la salud mental individual, y con ello, las relaciones sanas entre las personas y grupos en la sociedad..$^{31}$ El capítulo pretende animar la discusión y la acción práctica, refiriendo a tal fin experiencias ${ }^{32}$ de diversos países sobre cómo trabajar la salud mental en la escuela. Al igual que en el Apéndice, se dedica un amplio apartado al diagnóstico y el contenido y aplicación de los test.

El planteamiento ampliamente abarcador de todo el texto da cuenta de los horizontes de la propuesta psicoeducativa. Los análisis y consideraciones que componen la obra

publicaciones de la época con las que se pretendía recoger el sentir colectivo como el ensayo basado en encuestas de Fernando Gutiérrez, Los españoles y la educación sexual (Barcelona: Fontanella, 1974). Para un análisis, ver: Inma Hurtado García y Aida Terrón Bañuelos, "La educación sexual durante la transición: Modelando discursos y modulando voces", en Genealogías de la reforma sanitaria en España, 155-191.

${ }^{26}$ Wall, Educación y Salud Mental, 8.

27 Ibídem, 9.

${ }^{28}$ Ibídem, 343.

${ }^{29}$ Ibídem, 354.

${ }^{30}$ Ibídem, XIV.

31 Ibídem, 359.

${ }^{32}$ Entre ellas: programas de radio con charlas improvisadas entre el psicólogo escolar y grupos de niños/as, esquemas de lecciones en los que se traten "las relaciones humanas en clase", cursos de formación para personal docente, servicio psicológico para niños con trastornos relativamente graves, programas de educación de padres y clases de relaciones humanas, etc. Ibídem, 359-373. 
perfilan lo que será la arquitectura de la educación escolar en los países desarrollados tras la formalización de la enseñanza para todos, tanto en los aspectos estructurales y organizativos -cursos y niveles-como en los metodológicos y pedagógicos. Sin embargo, esta arquitectura omnicomprensiva -y extensa, considerando sus 445 páginas- también conlleva un estrechamiento de los planteamientos sobre salud mental escolar al prescindir de otros enfoques más sociales o psicoanalíticos. Este documento, y otros que surgen en esta década, permiten observar la inauguración de campos científicos que quieren hacerse un espacio académico y profesional. En todos estos discursos, el docente es un profesional considerado como una pieza clave en el desarrollo de la educación, pero siempre bajo la guía de quienes disponen del conocimiento experto. Esa es justamente el asunto objetado por el movimiento Freinet que vemos a continuación.

\section{La escuela y sus maestros como promotores de la salud mental: Célestin Freinet}

La colaboración de los enseñantes con médicos y especialistas de la salud de los escolares (también la mental) se venía requiriendo en esos mismos años por expertos de la Organización Mundial de la Salud (OMS) y, particularmente, de la Unión Internacional para la Educación Higiénica de la población (UIESP), como condición para el desarrollo efectivo de los programas de educación sanitaria escolar. ${ }^{33}$ Los maestros y profesores fueron percibidos como colaboradores imprescindibles de médicos y sanitarios dado el privilegiado observatorio que ofrecía la escuela para identificar el comportamiento, estado y evolución de su alumnado. También por su conexión y capacidad de influencia sobre la comunidad y las familias y, sobre todo, para modelar individuos con los que compartían días, meses y años (unas 10000 horas a lo largo de la enseñanza primaria). En conjunto, la situación idónea requerida por unas enseñanzas (sanitarias) que, más que conocimientos académicos o disciplinares, buscaban imprimir hábitos y conductas susceptibles de crear en los sujetos una "conciencia sanitaria" que se tornase indeleble.

En la guía preparada y editada en 1960 por la OMS-UNESCO sobre Preparación del maestro para la educación sanitaria, se perfila la formación requerida por este "colaborador" al que se le reservan importantes y subordinadas tareas dentro del organigrama. Médicos, psicólogos, psiquiatras, sanitarios, incluso trabajadores sociales auxiliares, habían de proporcionarle pautas en un sentido similar al planteado en la referida Conferencia sobre Educación y Salud Mental, que apuntaló el papel de la psicología canalizada en unos servicios de Orientación escolar percibidos como pieza sustantiva del cambio y la mejora. Según la propuesta que había hecho Zazzo desde el modelo francés, sus funciones se vinculaban expresamente a la dinámica escolar y al asesoramiento y apoyo de los enseñantes, exigiendo que los orientadores fuesen previamente docentes que se especializaban en psicología liberándose para ejercer dicha función. Solo unos años después será en Francia, justamente, donde un potente movimiento de maestros rechazará el juego de expertos/maestros. Y lo hará no tanto por oposición a las jerarquías, que también —como

\footnotetext{
${ }^{33}$ Aida Terrón Bañuelos, "La educación sanitaria escolar, una propuesta importada para la escuela española del desarrollismo", Archivos Analíticos de Políticas Educativas 23, no. 1 (2015). Disponible en: https://epaa.asu.edu/ ojs/article/view/1702.
} 
acabaría sosteniendo el enfoque de la pedagogía institucional-, sino situando en primer plano la virtualidad del espacio escolar y de sus "trabajadores", y particularmente de sus técnicas y metodologías, para promover, o por el contario lastrar, una acción terapéutica respecto de la salud mental de la infancia. Justamente la postura sobre la que desde los años treinta Freinet venía organizando "su" pedagogía conformadora de un Movimiento (el Movimiento Cooperativo de la Escuela Moderna) definido por la práctica de un conjunto de Técnicas desarrolladas a lo largo de varias décadas — bien en disputa o bien (lo que será más raro) en acuerdo - con algunos psiquiatras, médicos y psicólogos que se interesaron por las mismas.

La relación salud mental/escuela va a tener, efectivamente, en Freinet ${ }^{34}$ una consideración inequívoca, que la liga directamente a las buenas prácticas docentes, responsabilidad irrenunciable de los propios maestros y maestras. Las secuelas dejadas por la guerra en la infancia en forma de enfermedades físicas y trastornos mentales, poblaron las escuelas de tal modo que no les era posible obviarlas (incluyendo las víctimas de la guerra civil española refugiadas en Francia, algunas de las cuales Freinet, entonces militante comunista, acogió en su escuela).De otro lado, la dinámica fabril o de campo de concentración que con frecuencia presidía el hacer escolar en la década de los cincuenta —analogía que Freinet extrae de su propia experiencia como confinado-, pesaba sobre los niños, pero también sobre los maestros, igualando, en su opinión, la condición de trabajadores de la educación con la de los obreros o los mecánicos, estos enervados por el ruido o por una máquina que no funciona e insertos aquellos en un igualmente pernicioso engranaje, alterado por niños difíciles, ruidos y presiones diversas que acaban provocando una fatiga nerviosa anormal en la clase. Confiando en sus técnicas para crear un clima mental más equilibrado, Freinet está convencido de que tanto las causas como las soluciones del "desorden" mental que provocan las exigencias escolares — tan lesivas, además, por el nuevo orden meritocrático que las organiza y justifica en el contexto de la escuela para todos-, han de encontrar su respuesta en el ámbito de la escuela, en sus métodos y en sus maestros y maestras, los más interesados en el conocimiento del niño que la psicología escolar pregona. Estudiar (con otros expertos) el papel de la escuela y del maestro en relación con la salud mental fue la propuesta que, hecha y aprobada en la declaración final del XVI

\footnotetext{
${ }^{34}$ Maestro desde 1920, Freinet es adecuadamente definido por sus estudiosos como el artesano de la "pedagogía centrada en el niño". De su recurso a prácticas como el texto libre, el cine, el periódico escolar o los intercambios entre escuelas, da cuenta en 1927 el texto que acabará identificándole: La imprenta en la escuela. Funda con otros "socios impresores" la Cooperativa de la enseñanza laica (CEL). Instalado con Elise, su esposa, en Saint Paul, en 1929 comienzan a internacionalizarse los contactos con grupos escolares impresores que se apasionan por esta investigación cooperativa. Su carrera toma un giro en 1932 cuando es expulsado de la enseñanza pública. Apoyado por la CEL, abre en 1935 la Escuela Freinet en Pioulier (Vence). Maestro en los campos de prisioneros durante la II Guerra Mundial escribe, ya en libertad vigilada, sus obras importantes. Desde 1945, tras la Guerra, renace la CEL y el movimiento tiene un gran dinamismo: se crea el Instituto Cooperativo de la Escuela Moderna (ICEM), que concentra la investigación pedagógica de los miembros del movimiento; se aprueba la Carta de la Escuela Moderna; se funda la Federación Internacional de los Movimientos de la Escuela Moderna (FIMEM). A la vez que se han ido creando la Biblioteca de la Escuela Moderna, los Cuadernos pedagógicos, la revista Techniques de Vie y, sobre todo, el boletín L'Éducateur. Muere en 1966. George Piaton, "Freinet y la Escuela Nueva", Revista de Educación 242 (1976): 43-50.
} 
Congreso de su movimiento (París, 1958), Freinet pretendió que asumiese la UNESCO, solicitándole modificar la declaración de 1960 como Año internacional de la salud mental mediante el añadido "y de la educación", convencido de su interdependencia. Lo hizo en un congreso "maduro" 35 que contó por primera vez, además de con enseñantes, con algunos especialistas del campo de la psicología, la psiquiatría, la pedagogía y la medicina, que estaban mostrando cierto interés por sus métodos y técnicas. En su exhortación, contrastaba el ingente desarrollo científico que permitía trazar milimétricamente la trayectoria de los cohetes espaciales que rusos y americanos estaban lanzando al espacio, sin que, paradójicamente, ninguna ciencia se revelase capaz de "medir la trayectoria de los niños que nacen a la vida". ${ }^{36}$ Y en esa línea apelaba a que "psicólogos, pedagogos, psicoanalistas, psiquiatras, padres, organizaciones políticas y sindicales estudiasen, metódicamente, el problema de la infancia y su futuro". ${ }^{37}$

Alerta, sin embargo, de los riesgos de hacer un enfoque reduccionista del problema si se centraba en los "casos tratados en consultas, clínicas y hospitales", excluyendo así a tantos niños que sin pasar "esas redes", sin ser "sujetos de la medicina", no por ello son menos "deficientes". Reclama, frente a ello, amplitud de miras y colaboración ${ }^{38}$ para llegar a tantos otros a los que la escuela, ella sí, es capaz de ver: "aquellos que se ven privados o frustrados de afectividad, los tímidos, los faltos de audacia, los verbosos, los falsos intelectuales, los maníacos, los disléxicos". ${ }^{39}$ La lente había de ser más radical y abierta a identificar las condiciones de vida de la infancia y las instituciones que operan sobre el niño y su psique, particularmente la escuela y la familia. Los efectos perniciosos de aquella sobre la salud mental escolar procedían de un sistema que obligaba a la realización de un trabajo cuyo objetivo no se comprende; que conformaba un medio amoral, autoritario y competitivo; que habituaba a la pasividad, frenando las fuerzas vivas de la infancia, y perturbaba el psiquismo, desdoblando la personalidad, comprometiendo la afectividad y suscitando fobias y complejos. ${ }^{40}$

Desestimada por la UNESCO, la propuesta se volcó hacia el interior del movimiento, convirtiendo el estudio propuesto en objetivo prioritario de análisis e investigación en los

\footnotetext{
${ }^{35}$ Célestin Freinet, "Un congrès qui marque d'une façon décisive la grande maturité de notre mouvement de I'Ecole Moderne", L'Éducateur 19 (1958): 1-7. Disponible en: https://www.icem-freinet.fr/archives/educ/57-58/19/ educ_19_57-58.pdf.

${ }^{36}$ Célestin Freinet, "Pour une année international de l'éducation", L'Éducateur 3 (1958): 8-10. Disponible en: https://www.icem-pedagogie-freinet.org/node/38687.

${ }^{37}$ Ibídem, 8-9.

38 "Debemos buscar, juntos, el origen de su mal para descubrir sus remedios, alguna terapéutica de la que puedan valerse... los propios médicos no podrán, durante los trabajos en profundidad que acometerán este gran año de 1960 desdeñar este aspecto educativo del problema ... deberán considerar esta interdependencia de los problemas de psicología, pedagogía, formación, educación, por un lado, y salud mental, por el otro". Célestin Freinet, El equilibrio mental de niño (Barcelona: Laia, 1978): 27-28.

${ }^{39}$ Célestin Freinet, "Les soucis d'Éducation doivent s integrer aux travaux de l'Année internationale de la santé mentale", L'Éducateur 9 (1959): 28. Disponible en: https://www.icem-freinet.fr/archives/educ/58-59/9/1-3.pdf

${ }^{40}$ Célestin Freinet, "La pédagogie Freinet de l'Ecole Moderne et la santé mentale des enfants et des maitres (prévention y cure)", L'Éducateur 17 (1959): s. pag. Disponible en: https://www.icem-freinet.fr/archives/educ/5859/17/3-5.pdf.
} 
años siguientes, cuyos resultados serían presentados y debatidos en los Congresos de 1960, celebrado en Avignon con el título de La pedagogía Freinet de la Escuela Moderna y la salud mental de niños y maestros (prevención y cura), y en el de Annecy (1964) sobre Las enfermedades escolares.

A la altura de 1959 se insistía, no obstante, en observar las líneas de trabajo que proponían los organizadores del Año internacional de la salud mental, entre las cuales se incluía (¿como concesión a Freinet?) el estudio de las necesidades de los niños en el ámbito de la salud mental. Planificando concretamente la contribución de la Escuela Moderna, Freinet espoleó el compromiso de sus camaradas para la realización de un estudio riguroso y macro (¡"hagamos cientos, miles de monografías"!) acerca del efecto de "nuestra pedagogía de expresión libre y trabajo" sobre la salud mental de "nuestros" alumnos (nótese que las encuestas y monografías se harán por los maestros sobre su propio alumnado). Se acumuló así el material aportado al ya mencionado XVI Congreso Internacional del Movimiento de la Escuela Moderna celebrado en Avignon en 1960, con un primer título provisional - La pedagogía Freinet de la Escuela Moderna y la salud mental de los niños (prevención y cura)- finalmente retocado. Se trataba de incursionar en una problemática que era el pan de cada día de los docentes pero que ahora debía documentarse mediante una amplísima investigación, colectiva y centralizada (a coordinar por la Comisión de conocimiento del niño, del movimiento, activa desde hacía unos años), realizada con rigurosas metodologías científicas -encuestas escolares, familiares y sociales, y, sobre todo, monografías-, "que ponga negro sobre blanco nuestras constataciones", huyendo de generalizaciones gratuitas: "hechos precisos, medidos, notados, fotografiados, incontestables". ${ }^{41}$ Lo que el movimiento debía demostrar en Avignon, quedó nítidamente formulado por Freinet en el taxativo enunciado con el que prologó el dossier de materiales que, fruto de ese trabajo, fueron preparados para el congreso: "las técnicas Freinet mantienen 0 restablecen la salud mental de los niños". ${ }^{42}$

Podría decirse (estamos trabajando actualmente el asunto) que en el Congreso de Avignon se apostó por la toma en consideración de la contribución que, desde diversas ciencias y prácticas, otros profesionales podían hacer a la revisión del "sistema Freinet" de una manera cooperativa e integradora, ayudando(nos) a identificar y repensar "la situación de la escuela en el contexto científico, filosófico y social del mundo contemporáneo", a partir de la cual reorientar las medidas capaces de afrontar los desequilibrios (también el mental) que los tiempos, con su escuela-cuartel, según feliz formulación de Fernand Oury, ${ }^{43}$ agudizaban. Pero los pequeños atisbos de cooperación entre especia-

\footnotetext{
41 Ibídem.

${ }^{42}$ Célestin Freinet, La santé mentale des enfants, (Cannes: Editions de l'école moderne française, 1961): s.pág. Disponible en: https://www.icem-pedagogie-freinet.org/node/18126.

${ }^{43}$ Fernand Oury, maestro parisino, había comenzado en 1949 a aplicar las técnicas Freinet en las duras escuelas-cuartel de los suburbios. Era hermano del psiquiatra Jean Oury, quien desde el análisis institucional, apreciaba significativas similitudes entre la organización hospitalaria y la escolar, ambas instituciones totales y cerradas. En 1961 se produce una escisión, procediendo Fernand, junto con otros maestros, a montar otras
} 
listas y enseñantes se resquebrajaron pronto. Su aproximación a la mirada etnográfica y a la perspectiva "psi" (psicólogos, psiquiatras, psicoterapeutas) experimentará aún algunos fructíferos tanteos, pero terminará generando, inmediatamente, una escisión en el seno del movimiento, con la salida de la organización de un pequeño grupo de París, el más cercano a esos campos.

En los años siguientes surgirán distintas líneas con distintos acentos, metodologías y profesionales en la consecución del equilibrio en el seno de la escuela. Freinet y su movimiento trataron de articular una escuela más saludable. Partiendo de un marco de referencia más sincrético, utiliza, sin embargo, una metodología más holística y mantiene una posición epistémica más situada. Las divergencias de acentos supusieron la división en el seno del grupo, pero también dan cuenta de que este se nutría de una variedad de perspectivas que indudablemente modelaron las diferentes propuestas. Las metodologías, aunque tuvieran una orientación pedagógica y no de análisis social, permitían la elaboración y uso de datos etnográficos con los que incorporar la posición del individuo en la trama social y la propia voz de educadores y educandos, generando así unos saberes más horizontales sobre la vida en la escuela.

Asimismo, y este va a ser uno de los elementos que más contrasta con otros enfoques, Freinet amplía y desborda las competencias que se le suponían a la subordinada condición de maestros y profesores. Desmonta la relación de subordinación que se estaba apuntalando entre quienes hacen, quienes piensan y quienes piensan lo que otros hacen (o deben hacer). El maestro será el artífice de la praxis, pero también de la teoría con la que alumbrar la praxis docente, algo que planteaban también, ya en los cincuenta, los promotores de la Action Research (Investigación-acción). Esta perspectiva fue abonando un conflicto soterrado dentro del movimiento e influyó notablemente en la escisión.

\section{De la higiene mental a la salud mental escolar durante el tardofranquismo. Algunos referentes}

En la España de los años sesenta, los planteamientos sobre salud mental escolar tienen eco en ciertos sectores profesionales, si bien muy escaso impacto en la pedagogía española, prácticamente reducido a la traducción y edición de algunas obras clave, en ocasiones a instancias oficiales o paraoficiales, a las que vamos a prestar cierta atención. Es curioso que, de los cuatro autores a que vamos a referirnos, tres de ellos (Georges Mauco, Clément Launay y Julián de Ajuriaguerra) mantengan contactos con el Movimiento de la Escuela Moderna de Freinet (en algún caso incluso colaboran), y todos ellos reconozcan lo apropiado de sus técnicas en favor de una buena formación de la personalidad del alumnado.

Por orden cronológico de publicación, comenzamos citando a Mauco, médico de orientación psicoanalítica, director del Centro Psicopedagógico Claude Bernard de

dinámicas que culminarán con la creación de la pedagogía institucional. Ver: Antonio J. Colom, La pedagogía institucional, (Madrid: Editorial Síntesis, 2000). El nicho de surgimiento puede verse en la obra de Fernand Oury y Aida Vásquez, Hacia una pedagogía institucional (México: siglo XXI, 1967). 
París, y con una amplísima experiencia de trabajo en gabinetes de colegios y consultorías. Presenta en la ya referida Conferencia sobre salud mental y educación el trabajo "Problèmes psychologiques de l'adolescence: Les échecs scolaires et les difficultés d'adaptation au niveau secondaire et supérieur en France", y sabemos que asiste al congreso de la Escuela Moderna (París, 1958), participando en una sesión de trabajo en la que el grupo de Fernand Oury —en el que también participaba su hermano psiquiatra Jean Oury — presentaba sus análisis sobre la inadaptación escolar. En España fue invitado a impartir un ciclo de conferencias sobre "La inadaptación escolar" en el Instituto Municipal de Educación de Madrid ${ }^{44}$ coincidiendo con la traducción y publicación de su obra por la editorial Morata: Psicoterapia escolar. La inadaptación escolar y social y sus remedios (1962). Una edición que facilitó el acceso en lengua española a su trabajo, si bien sabemos que ya en 1959, año de su publicación original, Adolfo Maíllo se servía de ella en un artículo sobre la disciplina escolar, un asunto de capital importancia en cuanto que de su manejo por el maestro dentro del aula se hacía depender, en buena parte, "el clima de la clase", piedra angular de la acción educadora. De hecho, en un texto oficial para oposiciones del magisterio primario del que hablaremos posteriormente, las ideas de Mauco formarán parte de las consideraciones para entender la relación maestro-alumno en el marco escolar. La idea es que en su condición de único adulto en esa nueva sociedad que es el aula, en la que representa el conocimiento y la autoridad, el maestro desempeña, sin embargo, un doble rol, instructivo, desde luego, pero también un rol de respuesta a las transferencias del grupo y de cada uno de sus individuos, que exige un grado importante de madurez afectiva por parte del maestro. En 1969 se tradujo Psychanalyse et éducation, ${ }^{45}$ publicada con el mismo título por la editorial Carlos Lohlé.

Es también Maíllo quien promovió la traducción y publicación, en 1963, de la importante obra de Wall, ya analizada (Educación y salud mental), siete años después de su edición original. En su calidad de director, desde su creación en 1958, del Centro de Documentación y Orientación Didáctica (CEDODEP), un organismo técnico del MEC, Maíllo mantenía una conexión intensa con los análisis y orientaciones que en esos años estaban promoviendo la UNESCO y el BIE en pro de una reforma curricular de la escuela europea. Y en ese sentido, esta emblemática obra, que recurría e incorporaba el conocimiento psicológico para precisar el nuevo "encaje de piezas" de la escuela psicológica, tenía un claro interés para los profesionales de la educación. Debe recordarse que era ese mismo afán divulgativo el que había llevado a Maílo a implementar las propuestas de educación sanitaria escolar emanadas de esos organismos (así como la OMS y la UISPE), dedicándoles un monográfico de la revista Vida Escolar ya en 1961, si bien en él el tratamiento de la salud mental se reducía a un solo

\footnotetext{
44 "La inadaptación escolar", $A B C$ (18 de febrero de 1962): 95.

${ }^{45}$ Georges Mauco, Psychanalyse et éducation (París: Aubier-Montaigne, 1968). Trad. cast. Psicoanálisis y educación (Buenos Aires: Carlos Lohlé, 1969).
} 
artículo, el de Rof Carballo, sobre "La higiene mental del maestro". ${ }^{46}$ Raquel María Payá Ibars escribió sobre los problemas de la adaptación escolar y social y Serigó sobre la higiene del trabajo escolar. ${ }^{47}$

Otra pieza clave a la luz de las ideas y referencias bibliográficas que van a circular entre los "reformadores" españoles fue La higiene mental del escolar, de Launay. Esta obra, publicada en Francia en 1959, sería traducida por Concepción Sainz Amor, como "edición especial para el Ministerio de Educación y Ciencia"; ${ }^{48}$ lo cual constituye una clara muestra de la dinámica de apertura al conocimiento profesional por parte de la administración educativa española, haciendo accesible, en este caso, el mencionado libro de este catedrático de Medicina de la universidad de París, que había trabajado en gabinetes psicopedagógicos, así como, muy particularmente, dirigiendo, entre 1949 y1953 —por encargo expreso de la inspección escolar francesa-, cinco equipos psicopedagógicos puestos al servicio de las escuelas primarias de varias regiones francesas. Como Launay lo explica en la obra que referimos (muy derivada de esa experiencia) la labor técnica desarrollada iba expresamente dirigida a proporcionar ayuda frente a un problema muy generalizado en el sistema, al que atinadamente se refiere como "los comienzos erróneos de la evolución escolar", ${ }^{4}$ y sus consecuencias. En La higiene mental del escolar, obra que estructura siguiendo el modelo de historia clínica (anamnesis, diagnóstico y terapéutica) —de acuerdo con su condición de médico-, Launay caracteriza la compleja relación niño-escuela en el período de la edad de 6 a 10 años; precisando los motivos de consulta médico-psicopedagógica más frecuentes, sintetizando las cinco principales manifestaciones psicopatológicas de orden escolar (fracasos escolares, mentiras, fugas, fobias escolares e inestabilidad); dando cuenta de los problemas específicos de las materias básicas de enseñanza (lectura, ortografía, calculo, escritura) y la manera de afrontarlos, combinando terapéutica médica, técnicas pedagógicas particulares, psicoterapia, modificaciones introducidas en la vida escolar e intervención en el medio social.

Por último, queremos señalar un texto, posterior en el tiempo, proveniente también de una psiquiatría infantil de orientación psicoanalítica, que formará parte de los referentes

\footnotetext{
${ }^{46}$ Al final del mismo, en referencia a la contribución de ciertas disciplinas que pudiesen ayudar al maestro a enfrentar su compleja (y digna) tarea, destaca "un método del que no he hablado pero que estimo en esta cuestión fundamental: la psicoterapia de grupo... Pienso que, en el futuro, la "psicoterapia de grupo" y, sobre todo, las técnicas similares - tales como las que he expuesto para la formación del médico en medicina psicosomática en el Boletín del Instituto de Patología Médica, 15, 277, 1960-, jugarán un enorme papel en la formación del maestro; y acaso asimismo lleguen a jugarlo en el complemento formativo del sacerdote. Pero de ello no he querido hablar; en primer lugar, porque faltos de técnicos con suficiente preparación "auténtica", la psicoterapia de grupo en nuestro país corre el riesgo de diluirse y 'aguarse'. En segundo término, porque, para hablar de ello, ajustándonos al principio fundamental de estas técnicas, que es ver como la verdad surge en la propia práctica, sería menester, antes, hacer estudios 'piloto' o seminarios de ensayo y observar cuidadosamente, con objetividad, sus resultados". Rof Carballo, "La higiene mental del maestro" Vida Escolar 26 (1961): 35.

${ }^{47}$ Aida Terrón Bañuelos, "La educación sanitaria escolar, una propuesta importada para la escuela española del desarrollismo". Archivos Analíticos de Políticas Educativas 23, nº1 (2015). Disponible en: https://epaa.asu.edu/ ojs/article/view/1702.

${ }^{48}$ Clément Launay, La higiene mental del escolar (Barcelona: Luís Miracle, 1968).

49 Ibídem, 5-6.
} 
con los que pensar la salud mental escolar en la España de los setenta. Se trata del Manual de Psiquiatría infantil de Ajuriaguerra, editado en España en $1973,{ }^{50}$ que tuvo una relativa influencia sobre sectores de la educación más progresistas, debido, seguramente, al hecho de que un tratado sobre los trastornos infantiles abordase, específicamente, consideraciones expertas sobre "El niño y la escuela", haciendo accesibles consideraciones útiles y lúcidas procedentes de un campo de conocimiento muy alejado de su esfera. $\mathrm{El}$ niño y la escuela se analizaban aquí en distintos círculos de relación - "el niño, la escuela, los padres y el profesor"; "las dificultades escolares del niño" (la fobia escolar, el problema psicopatológico planteado por el fracaso escolar, el retraso escolar)—, a partir de cuyos análisis se derivaban consideraciones que ponían finalmente en "tela de juicio" a la propia escuela, lo que en los primeros años setenta constituía el caballo de batalla de análisis críticos en alza, como los sostenidos en obras emblemáticas por Illich, Reimer o Goodman sobre la desescolarización o la muerte de la escuela, bastante difundidas en los ámbitos pedagógicos.

El juicio a la escuela hecho por Ajuriaguerra se sostiene en potentes estudios sociológicos sobre el sistema educativo francés que, apoyados en una amplia estadística, evidenciaban el inequívoco filtro de clase social en los resultados escolares, tal como documentaban, entre otros, Bourdieu y Passeron. ${ }^{51}$ Una escuela que filtra y selecciona (mediante repeticiones o no otorgación del CEI) no puede negar la categoría de "normal" a aquello que excluye o deja fuera —un alto porcentaje del alumnado-, ya que "no se puede considerar que un curso escolar sirva para la población en general cuando las dos terceras partes de escolares no llegan a seguirlo"52 (citando a C. Chiland). Un fracaso escolar que alcanza a la mitad de la población no puede abordarse acudiendo a la "peligrosa salida" de "medicalizar" - por no decir "psiquiatrizar" - el problema, evitando con ello hacer un real "balance de responsabilidades". ${ }^{33}$ Seducidos por este enfoque, algunos sectores docentes valorarán también el cuestionamiento de la perspectiva fisiologista y la búsqueda de causas más estructurales a las patologías sobre los trastornos del lenguaje oral y escrito, cuestionando la etiqueta convencional y totalizadora de "dislexia", tan utilizada en esos años. ${ }^{54}$ Probablemente sea el modo integral de concebirlos, insertándolos dentro del marco condicionante de la escuela, lo que favoreciese esa pregnancia, al menos entre muchos enseñantes y pedagogos. Debe señalarse, finalmente que Mauco, con sus análisis sobre la figura psicológica del maestro, los de Launay sobre el tratamiento de la fobia escolar, y los enfoques de la nueva pedagogía "especialmente la de Freinet"55, son apoyos claros del argumentario de Ajuriaguerra que estamos considerando.

\footnotetext{
${ }^{50}$ Julián de Ajuriaguerra, Manual de Psiquiatría infantil (Barcelona: Toray Masson, 1973).

${ }^{51}$ Bourdieu y Passeron, La reproduction. Éléments d'une théorie du système d'enseignement (París: Minuit, 1970).

${ }^{52}$ Julián de Ajuriaguerra, Manual de Psiquiatría infantil (Barcelona: Toray Masson, 1973), 829.

${ }^{53} \mathrm{lbídem}$

${ }^{54}$ El título del libro más influyente entre los citados sectores de los profesionales de la educación sería, precisamente, el de La dislexia en cuestión (Madrid: Pablo del Río, 1977), en el que colaboraron diversos especialistas, Ajuriaguerra entre ellos.

${ }^{55}$ Ajuriaguerra, Manual de Psiquiatría infantil, 829.
} 


\section{Las pautas para la acción: Prandi y la estela OMS-UNESCO}

La educación sanitaria escolar modelo OMS-UNESCO se perfiló, a nuestro entender, en dos trabajos canónicos: la obra de Clair Elsmere Turner Planeamiento de la educación sanitaria en las escuelas", ${ }^{6}$ enfocada desde una perspectiva predominantemente médica, y las conclusiones de la Conferencia de expertos - en este caso docentes, administradores de la educación, psicólogos, sexólogos- celebrada en Hamburgo en 1964 sobre "salud, sexo, vida familiar", recogidas en un texto del mismo título. ${ }^{57}$ Francesc Prandi, director del Departamento de Pediatría del Hospital San Rafael de Barcelona, podría representar este modelo OMS-UNESCO en su versión española. De tal manera va a orbitar sobre este modelo, que llega reproducir literalmente en sus trabajos las instrucciones de Turner para el magisterio primario sobre la salud mental escolar. ${ }^{58}$

Será Maíllo quien, en su calidad de director de la Enciclopedia de didáctica aplicada, ${ }^{59}$ cuente con la colaboración de Prandi como voz autorizada en educación sanitaria. Se trata de una obra que estaba destinada al ámbito académico de la Pedagogía, y expresamente a la formación de maestros, haciendo de ese modo accesible y confiriéndole cierta difusión al modelo OMS-UNESCO. En su contribución —el capítulo titulado "Fisiología e higiene y educación sanitaria"- Prandi presenta la salud mental como resultado de la higiene del sistema nervioso, proponiendo, genéricamente, no fatigarlo, evitando cuantas circunstancias físicas, ambientales o tóxicas puedan contribuir a ello (ruidos, excitantes, los ambientes caldeados, locales cerrados), y advirtiendo del efecto en el sistema nervioso del miedo y el temor a los castigos. ${ }^{60}$ Como corresponde a una "enciclopédica aplicada", el autor propone, en un concentrado de siete principios de actuación, ${ }^{61}$ las prescripciones relativas a la higiene mental del sistema nervioso de su alumnado, muy similares a los enunciados por Turner.

\section{Ámbito escolar: el impulso de Maíllo}

Entre los años sesenta y ochenta la salud escolar recibirá escasa atención en el ámbito académico y en la prensa pedagógica. Son muy esporádicas las menciones en las revistas oficiales Vida Escolar, Revista de Educación u Orientación Pedagógica (el Boletín de la Inspección de enseñanza primaria, en cuya sección "charlas para maestros" aparecen

\footnotetext{
${ }^{56}$ Clair Elsmere Turner, Planeamiento de la educación sanitaria en las escuelas (Barcelona: Teide, 1967).

${ }^{57}$ Ver: UNESCO, Health education, sex education and education for home and family life (Report on an Expert Meeting), (Hamburgo: UNESCO Institute for Education, 1965). Disponible en: https://unesdoc.unesco.org/ ark:/48223/pf0000131553 La versión castellana, Educación para la salud, el sexo y la vida familiar (Buenos Aires: Paidós, 1971).

${ }^{58}$ Turner re-expone y resume en apartados de su texto lo que se hace (o se propone) en decenas de países. En lo relativo a vida escolar higiénica (13 principios de actuación) incluye: V: estimular las relaciones entre maestros y alumnos para crear un ambiente agradable en la clase que evite en los alumnos el temor y la tensión nerviosa y les permita aprender con provecho, y VIII: organizar la clase evitando la fatiga, considerando la capacidad física y mental y la diversidad de intereses y estado de salud de los alumnos.

${ }^{59}$ Adolfo Maíllo (ed.), Enciclopedia de didáctica aplicada (Barcelona: Labor, 1974).

${ }^{60}$ Francesc Prandi, "Fisiología e higiene y educación sanitaria", en ibidem, 611.

${ }^{61}$ Ibídem, 611-612.
} 
algunos comentarios-consejos-indicaciones). Un rastreo sistemático de las mismas ha arrojado una producción tan escasa que apenas merece la pena citarla. Es cierto que la reforma que se inicia con la Ley de enseñanza primaria de 1965 y que se cierra con la Ley General de Educación de 1970, impulsó algunas actuaciones dentro del CEDODEP que cabría mencionar. La entidad que entonces adquiere la figura del director de grupo escolar tras la ampliación de la escolaridad obligatoria hasta los 14 años, y la consiguiente transformación de escuelas en grupos escolares, así como la actualización y modernización que experimenta la función inspectora (que pasará a denominarse "supervisión escolar") requirió la convocatoria de sendos cursos de formación, en 1965 para los primeros y en 1966 para los segundos. En ellos el campo de la salud mental escolar aparece de manera muy oblicua en el primero, Orientaciones pedagógicas para los directores escolares, ${ }^{62}$ con tratamientos sobre los test y la medida de la inteligencia, la vida afectiva del escolar, la orientación escolar y la ficha psicopedagógica del alumno; y de manera directa en el segundo, Organización y supervisión de escuelas. En este último, Maíllo ${ }^{63}$ presenta una ponencia sobre "El servicio social escolar", mientras que Serigó, inspector médico escolar y Secretario del PANAP, lo hace sobre "Servicios escolares: Médico y Psicológico". Le avala una obra fundamental sobre Higiene escolar, ${ }^{64}$ divulgada en artículos y conferencias relativas básicamente a la inadaptación escolar y a los trastornos de lecto-escritura.

Por último, queremos recuperar un texto de gran interés para identificar el criterio oficial acerca del conocimiento necesario al magisterio en esta fase de reforma que conduce a la ley de 1970, texto que desconocíamos y que podría dar mucho juego a la investigación histórico-educativa de ese período. Se trata del titulado Ciencias de la Educación. Contestaciones al cuestionario oficial de las oposiciones a ingreso en el magisterio nacional (convocatoria 1970), ${ }^{65}$ en el que colabora, junto a otros, Maíllo. Responde a un momento en que se está intentando elevar el estatuto epistemológico de la Pedagogía en esta fase profesionalizadora; de ahí que los cincuenta temas recogidos codifiquen un conocimiento especializado para guiar el quehacer de los maestros (psicológico, sociológico, estadístico, científico-metodológico, organizativo, didáctico y filosófico), relación que identifica las futuras Ciencias de la educación, que acabaran sustituyendo, incluso en la denominación de la Facultad correspondiente, a la Pedagogía. Cada una de ellas presenta aquí su contribución a la articulación de una educación integral, y concretamente al asunto que nos ocupa, afirmándose al respecto que la escuela debe ser la institución "más eficaz respecto a la higiene mental", y que "no hay factor pedagógico que concierna a la escuela más íntimamente que las causas de las dificultades mentales del niño, sus inadaptaciones y desórdenes de conducta, así como su prevención y remedios". El maestro -y aquí vemos

\footnotetext{
${ }^{62}$ Ministerio de Educación Nacional, Orientaciones Pedagógicas para directores escolares (Madrid: CEDODEP, 1965).

${ }^{63}$ Adolfo Maíllo, "El Servicio social escolar", en Organización y supervisión de escuelas, Ministerio de Educación Nacional (Madrid: CEDODEP, 1966), 137-152.

${ }^{64}$ Adolfo Serigó Segarra, Medicina e higiene escolar. Introducción a la Medicina Pedagógica (Madrid: Cultura Clásica y Moderna, 1958).

${ }^{65}$ VVAA, Ciencias de la Educación. Contestaciones al cuestionario oficial de las oposiciones a ingreso en el magisterio nacional (convocatoria 1970) (Madrid: Escuela Española, 1970).
} 
la perspectiva de Mauco, y también la de Wall— procurará la estabilidad de carácter de sus alumnos, mediante una orientación comprensiva que le ayude a enfrentarse con las tensiones y angustias de la vida con una mente normal y saludable, lo que implica entender "que ningún maestro es simplemente un instructor de matemáticas, de historia o cualquier otra asignatura, sino que todos los maestros son constructores de carácter" ${ }^{66}$

\section{Los cuadernos para la educación en salud mental}

En el ámbito de la salud van a introducirse en España nuevos conceptos como salud mental, psiquiatría social y asistencia comunitaria que, impulsados desde las "Recomendaciones" de la OMS y otros organismos internacionales, pasan a formar parte de los discursos y las prácticas psiquiátricas. En ese periodo se transita del término higiene mental al término y al modelo de atención de salud mental. ${ }^{67}$ Como documentan las investigaciones de Enric Novella $(2017,2019){ }^{68}$ y David Simón Lorda, ${ }^{69}$ este contexto renovador enmarca el surgimiento del Patronato Nacional de Asistencia Psiquiátrica (PANAP) del que Serigó, psiquiatra de formación, será su segundo y último secretario general, tras su paso por la Inspección médico-escolar del Estado. Desde el PANAP se va a impulsar la Unidad de Educación en Salud Mental que pone en marcha proyectos formativos y divulgativos como la revista Salud Mental y los CESM. La edición de estos se extendió de 1974 a 1979, y en ella participaron, sucesivamente, la Dirección General de Sanidad dependiente del Ministerio de Gobernación hasta 1973 y, posteriormente, de la Subsecretaria de la Salud del Ministerio de Sanidad y Seguridad Social.

Del análisis del marco institucional realizado por de Simón Lorda, ${ }^{70}$ interesa señalar que la colección tenía, también, una finalidad formativo-docente. El PANAP estaba empeñado en mejorar la educación y formación de los profesionales de la salud mental, particularmente del personal auxiliar (nótese que en 1974 se había puesto en marcha la Escuela de Ayudantes Técnicos Sanitarios -ATS - Psiquiátricos). El autor resalta este esfuerzo de Serigó, y sus equipos del PANAP, por potenciar "al personal que trabajaba en los centros de salud mental y asistencia psiquiátrica". ${ }^{71}$ Algún profesional de los Equipos de Salud Mental infantil de Asturias en los años ochenta, que conocía y manejaba estos cuadernos, confirma este criterio.

Serigó fue secretario general PANAP desde 1964 hasta su supresión en 1972, reingresando entonces a la Inspección médico-escolar del Estado (BOE 24-2-1973). Durante

\footnotetext{
${ }^{66}$ Ibídem, 211 y 213.

${ }^{67}$ Fabiola Irisarri, Psiquiatría crítica en España en la década de los 70, Tesis doctoral, Universidad Complutense de Madrid (2018).

${ }^{68}$ Ver: Enric Novella Gaya, "La psiquiatría franquista y la educación para la salud mental", 81-103. Disponible en http://libres.urv.cat/index.php/purv/catalog/download/264/299/653-1?inline=1, y "Los límites de la tecnocracia: La modernización autoritaria de la asistencia psiquiátrica en la España del segundo franquismo", Dynamis: Acta Hispanica Ad Medicinae Scientiarumque Historiam Illustrandam, 39, n¹ (2019): 73-97.

${ }^{69}$ Ver: Simón Lorda, "El Patronato Nacional de Asistencia Psiquiátrica (PANAP) y sus contradicciones", 15-46, y

"Atención psiquiátrica. Salud mental y salud pública en el tardofranquismo", 127-154.

70 Ibídem.

71 Ibídem, 132.
} 
esos diez años su atención a ese ámbito se redujo a una, por más que importante, intervención en el curso del CEDODEP ya mencionado, presentando allí unos (novedosos en nuestro país) Servicios escolares médico y psicológico, sus funciones y organigrama, encajándolos en las administraciones educativa y de Gobernación. Probablemente sea una actuación conectada de algún modo con el diseño del Plan dedicado a la Higiene Mental que entonces estaba elaborando, enmarcado en el Plan de actividades Sanitarias de la Dirección General de Sanidad (1965-1967)..$^{72}$ Obedece también a la responsabilidad de estos organismos técnicos de dirección (PANAP y CEDODEP) en la formación y el perfeccionamiento del personal de los distintos servicios en esos años del tardofranquismo, sean, desde el primero, los seminarios y cursos de divulgación para preparación de auxiliares y de directores de centros sanitarios, sean, desde el segundo, los dirigidos a inspectores y directores escolares que hemos referido.

Novella y Simón Lorda señalan la poca expansión que tuvieron las líneas de acción del PANAP, a la vez que lamentan el escaso reconocimiento historiográfico a su papel en la introducción del nuevo paradigma de la salud mental comunitaria. En lo que respecta al ámbito de la pedagogía, los CESM pasaron completamente desapercibidos, sin presencia reseñable en publicaciones, cursos o actuaciones en el entorno de la salud mental escolar. En general, no aparecen citados ni forman parte del fondo bibliotecario de las facultades de educación. ${ }^{73}$ Pero nuestro interés en estos folletos no se deriva de su impacto - muy limitado-, sino del reflejo de algunas de las orientaciones sobre salud mental que estaban postulándose por aquel entonces. Los 51 folletos que componen ${ }^{74}$ la colección son muestra de un enfoque claramente psicosocial y de una visión muy moderna de la salud mental. Las temáticas, de muy amplio espectro, incluían desde el mundo de la vejez a la problemática familiar en un mundo en cambio, la jubilación, las relaciones con la empresa, la vida sexual, las drogas, las nuevas literaturas infantojuveniles (tebeos), la herencia, el alcoholismo, la enfermedad mental o el mundo laboral. Serigó refiere su intención divulgativa, destinada a "informar sobre los aspectos necesarios para el equilibrio humano, físico, psíquico y social"75 de manera sencilla y con profusas ilustraciones ${ }^{76}$ en todos los números.

\footnotetext{
72 Enric Novella Gaya, "Los límites de la tecnocracia: La modernización autoritaria de la asistencia psiquiátrica en la España del segundo franquismo", Dynamis: Acta Hispanica Ad Medicinae Scientiarumque Historiam Illustrandam, 39, no-1 (2019): 73-97.

${ }^{73}$ En realidad, 50 folletos, ya que uno de ellos abarca dos números. Los ejemplares físicos se localizan fundamentalmente -y este puede ser un indicio de sus destinatarios y usuarios- en facultades de enfermería, medicina y psicología, particularmente de las universidades de Madrid.

${ }^{74}$ Hay cuatro números (44-47) que no llegan a editarse. Puede que fueran algunos inicialmente previstos y que finalmente su autor/a no entregó. Tres anunciados en el no 8: Cambio de estructura en la zona de cuidados de los hospitales; El niño y sus abuelos; y Cambio social (anunciados en el $\left.n^{\circ}-8\right)$. $Y$ dos anunciados en el $n^{\circ} 6$ : El invento de la infancia y Los juegos del niño.

${ }^{75}$ Novella Gaya, "La psiquiatría franquista y la educación para la salud mental", 97.

${ }^{76}$ Las ilustraciones, en prácticamente todos ellos, son de Elteka David. Simón Lorda afirma que la OMS felicitará a esta ilustradora y pintora de origen húngaro, formada en Cuba y Madrid, que trabajó durante ocho años con el Ministerio de la Gobernación y luego con el de Sanidad. Ver: David Simón Lorda, "Atención psiquiátrica. Salud mental y salud pública en el tardofranquismo", en Genealogías de la reforma sanitaria en España, eds. José Martínez Pérez y Enrique Perdiguero Gil (Madrid, España: Catarata, 2020), 127-154.
} 
Como evidencia la relación de títulos que relacionamos en la nota, ${ }^{77}$ - prácticamente completa- ${ }^{78}$, la infancia y la educación (escolar) recibieron una atención privilegiada, hasta el punto de poderse identificar el intento de ordenar una confusa "serie infantil" con algunos números. Los títulos sobre formación de la personalidad del niño, psicología infantil, infancia y sexualidad, trastornos de la conducta infantil, los niños difíciles, los juguetes, los tebeos, los accidentes en la infancia, droga y juventud o sanciones escolares y salud mental, pueden dar una idea aproximada del perfil con el que se enfoca este ámbito y su relevancia para la mirada pedagógica y antropológica en la que nos situamos.

La variedad temática de los CESM es uno de los elementos más destacables junto con la amplitud de miradas profesionales hacia la salud mental. La mayor parte de autores son psiquiatras, más algún profesional de la psicología, la sexología o el trabajo social (ningún

${ }_{77}$ La herencia biológica, José Soria $(1,1976)$; Sanciones escolares y salud mental, Rafael Garde Enciso (2, 1974); El niño que quiere seguir siendo bebé, José Soria García (3, 1976); Los juguetes, Carlos Navarro (4, s.f.); El nacimiento del segundo hijo, Presentación Fernández (5, 1976); La enfermedad de los dirigentes: génesis, síntomas, prevención y tratamiento, Adolfo Serigó Segarra (6, 1975); Los tebeos. Carlos Navarro (7, 1975, 1977); La familia del enfermo mental, José Soria García $(8,1975)$; La familia en un mundo en cambio. Adolfo Serigó Segarra (9, 1975); La formación de la personalidad del niño, Adolfo Serigó Segarra (10, 1975); La familia y el niño, Adolfo Serigó Segarra (11, 1975); Inadaptación escolar, Adolfo Serigó Segarra (12, 1975); La violencia, amenaza para la salud psíquica en la escuela, Rafael Garde Enciso (13, 1975); Cambios psicológicos en la tercera edad, Jesús Sánchez Caro (14, 1975); Sexo y sexualidad, Efigenio Amezúa (15, 1975); El desarrollo del niño normal: de 0 a 5 años, Montserrat Castanyer (16, 1975); Concepto médico-psicológico de la adaptación social, Adolfo Serigó Segarra (17, 1975); La juventud en una sociedad en cambio, Adolfo Serigó Segarra (18, 1975); Los niños difíciles, Adolfo Serigó Segarra (19, 1975); La influencia del erotismo en la literatura actual, Adolfo Serigó Segarra (20, 1975); Educación integral y salud mental, Rafael Garde Enciso (21, 1975); Infancia y sexualidad, Efigenio Amezúa (22, 1975); Los subnormales, Amparo Ferrer (23, 1975); Vocación y aptitudes, Carmen Comeche Villanueva (24, 1975); Trastornos de la conducta infantil, Rafael Garde Enciso (25, 1975); La fatiga y los accidentes laborales, Adolfo Serigó Segarra $(26,1975)$; ¿Cómo responder a los interrogantes del niño sobre el sexo? Efigenio Amezúa (27, 1975); Adolescencia y sexualidad, Efigenio Amezúa $(28,1975)$; Trastornos de la lectura, Adolfo Serigó Segarra (29-30, 1975); Droga y juventud, J. M. Fernández, P. Navarrete y J. Castelo (31, 1975); La familia y la tercera edad, Jesús Sánchez Caro (32, 1975); Los accidentes en la infancia, José Luis Medina Barea $(33,1973)$; Grupos y organizaciones sociales, Adolfo Serigó Segarra $(34,1977)$; Relaciones humanas en la empresa, Adolfo Serigó Segarra $(35,1977) ;$ Adolescencia, José Luis Medina Barea $(36,1977)$; Los adolescentes y la gran ciudad, Jesús Sánchez Caro (37, 1977); Para comprender la menstruación, Efigenio Amezúa (38, 1977); Las enfermedades de transmisión sexual, A. de Ortega (39, 1977); La jubilación, Jesús Sánchez Caro (40, 1977); Problemas laborales, Carmen Comeche Villanueva (41, 1977); Incontinencia de orina (enuresis) y de heces (ecopresis), Amparo Rubio (42, 1977); Retraso mental (Oligofrenias), Amparo Rubio (43, 1977); Visión global de la psicología del niño, Adolfo Serigó Segarra (48, 1979); Alcohol y alcoholismo, Blas Curado García $(49,1979)$; Alcoholismo y sociedad. Blas Curado García (50, 1979); Prevención y tratamiento del alcoholismo, Blas Curado García $(51,1976)$.

${ }^{78}$ De difícil datación y localización, ha exigido la consulta de varias bases (finalmente CISNE fue la que nos proporcionó más información). Algunas cuestiones que cabe señalar es que en el n.ㅇ 8 figuran como títulos programados, luego no incluidos, los siguientes: Cambios de estructura en la zona de cuidados de los hospitales, El niño y sus abuelos y Cambio social. Es posible que alguno de ellos corresponda a los números 43, 44, 45 y 47 cuyos títulos no ha sido posible localizar, si es que fueron publicados. Asimismo hay un cierto descontrol en la periodicidad, en algunos datos e incluso (es el caso del no 7 ) una doble autoría: de Carlos Navarro en su primera edición, 1977, y de Etelvino González en la segunda, 1979). La no correlación secuencial entre el año de edición indicado y el número que cada folleto ocupa en la colección puede deberse bien al hecho de que, al no indicarse la edición, no sea posible conocer si la manejada es la primera u otra posterior, bien a que transcurrieran cierto tiempo entre la entrega del original y su publicación, bien a otras circunstancias editoriales que desconocemos. 
pedagogo). Una de las cuestiones que nos despertaba interrogantes era precisamente la conexión entre los diversos autores de la colección. Con los datos de algunas de sus trayectorias biográficas se identifican dos nexos: el Gran Hospital del Estado de Madrid (actual Hospital de la Princesa), donde estaba la Unidad de Educación en Salud mental, y la Universidad de Lovaina, centro académico superior con clara influencia, por su ideario católico, en la pedagogía y psicología universitaria de la España de mediados del siglo XX.

Una de las temáticas que se va a recoger en ese enfoque psicosocial y comunitario es la escuela, bien en el título del folleto, bien como ambiente a tener en cuenta en algunas de las problemáticas planteadas. Serigó es el autor más prolífico de la colección con catorce números de su autoría. Varios de ellos dedicados a las patologías del niño y del adolescente, algunas específicas del ámbito escolar, como los trastornos de la lectura o la inadaptación escolar, temáticas vinculadas a su condición de inspector médico-escolar y a las que venía dedicando una atención reiterada por sus efectos sobre el fracaso escolar. ${ }^{79}$ El sexólogo Efigenio Amezúa ofrece, en cinco números, una panorámica informativa sobre la dimensión sexual en la infancia y la adolescencia — que ya analizamos en otro lugar-, ${ }^{80}$ y el correcto enfoque que cabría hacer desde la higiene y la salud mental. Y, finalmente, un desconocido Rafael Garde Enciso es el autor de los cuatro volúmenes más directamente centrados en la salud mental escolar.

\section{Serigó Segarra: entre la Higiene escolar y la medicina pedagógica.}

La trayectoria y obra educativa de Serigó, nutrida de temas como la salud mental, la higiene escolar y la salud pública, es reconocida por su destacable amplitud de enfoque acudiendo a recursos antropológicos para el análisis de los problemas sociales de la salud mental. ${ }^{81}$ En el caso de los CESM, su labor es más discreta; no pierde amplitud, pero afecta al planteamiento en cuanto resultado del reciclaje de trabajos previos. Su obra más consistente, Medicina e Higiene escolar. Introducción a la medicina pedagógica (1958) servirá de guía parece establecer la relación de los temas a encajar en los CESM en relación con la infancia. Los folletos que "coinciden" o pueden derivarse de este extenso tratado, son, mayoritariamente, de autoría suya. Hemos podido constatar que en varios Cuadernos lo que hace es un volcado directo de capítulos, o parte de capítulos, cuestión no banal dados los veinte años transcurridos entre una publicación y otra.

En la Introducción de su tratado afirma que "aunque en esencia la Medicina e Higiene escolar es la Pediatría de la edad escolar" (recogiendo la formulación de Sainz de los Terreros), se trata de una materia compleja que quiere abordar desde diversas perspectivas.

\footnotetext{
${ }^{79}$ Para seguir la evolución de este gran mantra en nuestro país, véase el sistemático trabajo de Javier Rujas Martínez-Novillo, "La construcción del "fracaso escolar" en España. Génesis y cristalización de un problema social", Papers, 102/3 (2017): 477-507.

${ }^{80}$ Inma Hurtado García y Aida Terrón Bañuelos, "La educación sexual durante la transición: Modelando discursos y modulando voces", en Genealogías de la reforma sanitaria en España, 155-191.

${ }^{81}$ Elisa Alegre-Agís, Josep Barceló-Prats y Josep Maria Comelles, "La confusión de los psiquiatras. Las narrativas en torno a la crisis del custodialismo durante el tardofranquismo", Revista de Historia de la Psicología 39, no. 1 (2018): 31-39.
} 
Lo que constituye una temeridad, en opinión de Sainz de los Terreros, ${ }^{82}$ autor canónico del campo $0^{83}$ y prologuista de la obra, a quien la pretensión de esta "medicina pedagógica" de incorporar la mirada de diversas ciencias (medicina, pediatría, higiene, sanidad, psicología, psiquiatría, pedagogía, sociología, estadística...) le parece, utilizando un símil financiero, "una cartera de valores difícil de manejar", sin ahorrarse objeciones al respecto. Su valoración de esta extensa y compleja obra es, sin embargo, positiva ya que "si bien tomado de otras ciencias afines", hay aquí, nos dice, un cuerpo de doctrina (de higiene escolar) seleccionado y adaptado que le otorga "rango propio". ${ }^{84}$

Los apartados segundo y tercero de esta obra (tratado) de Serigó ajustan con los CESM. Concretamente del segundo -donde trata del crecimiento y desarrollo escolar, englobando aspectos físicos y psíquicos (biometría y biotipología, alimentación y nutrición; desarrollo desde el punto de vista psicológico) - derivan los cuadernos 10 y 48, ambos de su autoría, así como los números 28,36 y 37 , de autoría diferente. De la tercera parte, en la que desarrolla aspectos médico-pedagógicos relativos a los anormales físicos, sensoriales y psíquicos, la oligofrenia, la parálisis cerebral y la inadaptación escolar — "síndrome característico de la medicina escolar"85 - , se derivan los cuadernos 12, 19 y 29-30, todos de su autoría.

El autor va a recuperar otros de sus trabajos anteriores, relativos al "complejo problema de la inadaptación escolar", para volcarlos al cuaderno n¹2. Este término, que cubría una problemática de amplio espectro ya en los años sesenta, se desarrolla en Medicina e Higiene escolar en términos de síndromes - "síndrome de inestabilidad motriz constitucional"- y de dificultades específicas - "dislexia y dificultades para la aritmética"-, a las que debían ofrecer una respuesta técnica unos servicios escolares médico-psicológicos cuyo establecimiento, según hemos visto, preconizaba. De hecho, hemos suplido la carencia del cuaderno $n^{0}-12$ de la colección (Inadaptación escolar) a partir del tratado que manejamos (capítulo XIII) y de la ponencia en el mencionado curso del CEDODEP. ${ }^{86}$

Finalmente, la cuarta parte del tratado, dedicada a la asistencia médico-social del escolar, incluye la complejidad familiar y del entorno social, correlacionando con los números dedicados a la familia: el n 9 y el 11. Pudiendo concluirse que, a diferencia de los muy actualizados apoyos bibliográficos utilizados en Medicina e Higiene escolar, donde recoge autores como Wall o Launay, Serigó no actualiza los CESM, probablemente porque no esperaba que tuvieran gran difusión. Cierto que algunos números de los que es autor tienen bibliografía actualizada, concretamente los citados sobre la familia, pero también estos se

\footnotetext{
82 Serigó Segarra, Medicina e higiene escolar, Introducción a la Medicina Pedagógica (Madrid: Cultura Clásica y Moderna, 1958), 9.

${ }^{83}$ Director del Cuerpo médico-escolar del Estado, Sainz de los Terreros había publicado Higiene escolar en 1933.

84 Introducción a la Medicina Pedagógica (Madrid: Cultura Clásica y Moderna, 1958), 10.

${ }^{85}$ Ibídem, 15.

${ }^{86}$ Textos previos al folleto que nos ocupa sobre inadaptación serían: "Inadaptación escolar", Cuadernos de Orientación, Madrid (octubre 1958-junio 1959); "La higiene mental en las escuelas", Vida Escolar 21 (1960): 28-30.
} 
nutren de otra publicación anterior titulada Medicina preventiva y Social. ${ }^{87}$ La familia es un nudo gordiano en el discurso de la salud mental escolar en particular, y en general, centro de la investigación sociológica española en los primeros años setenta.

Hay otros colaboradores que trabajarán con una perspectiva mucho más moderna asuntos concomitantes con lo escolar, como es el caso del Cuaderno $n^{\circ}-23$ sobre los subnormales, de Amparo Ferrer, ${ }^{88}$ los ya citados de Amezúa sobre sexualidad, o los de Carlos Navarro sobre "los juguetes" y "los tebeos", que hacen un estudio, sobre todo este último, de grandísimo interés en un momento en que este género estaba causando el mismo furor y las mismas preocupaciones que años después causarán los videojuegos, por la indefensión del niño ante la sugestión de la imagen y el color, la impresionabilidad de unos contenidos que pueden causar daño mental, el recurso a la violencia, la agresividad y el instinto de crueldad, con personajes minimizados, en situación de humillación, identificación masoquista con ellos, relatos de horror, división maniquea de personajes en buenos y malos, etc. ${ }^{89}$ Como ya advertíamos, los aspectos de salud mental escolar abordados más directamente quedarán en manos del psicólogo Garde.

\section{Garde: el análisis institucional de la escuela}

Garde va a adoptar una perspectiva bastante novedosa en el seno de un tipo de colección que, a pesar de ser mayoritariamente médica, se abre a factores sociales y análisis institucionales, como es el caso. Dado que se desconoce bastante todo lo relativo a este autor, hemos recompuesto algunos datos que pueden contextualizar su contribución.

La semblanza de Garde que hemos alcanzado a hacer, proviene de los escasos datos de una peculiar trayectoria que nos lleva inicialmente al "prestigioso rector de nuestro Seminario de Tarazona" (2009), quien en una misa matutina afirmó que el reciente refe-

\footnotetext{
${ }^{87}$ Adolfo Serigó Segarra, Medicina preventiva y Social (León: Institución Fray Bernardino de Sahagún. Everest, 1972).

${ }^{88}$ Por su interés como documento de época referimos el planteamiento que desde ese campo de la subnormalidad se hace sobre la escuela. Cita en extenso la ponencia "Prevención y sociedad" que Alfredo Fierro presentó en las IV Jornadas Técnicas sobre Deficiencia mental, cuya cuarta conclusión afirma que "en su funcionamiento actual, la institución escolar produce una primera y fundamental marginación del subnormal, rechazándole y separándole de la escolaridad ordinaria. El sistema escolar produce subnormales. Hay que esforzarse al máximo para que la mayor parte de los retrasados escolares permanezcan incorporados a la escolaridad ordinaria, reforzada, quizá, mediante aulas de ayuda o unidades de rehabilitación. Merecen aplauso y estímulo las experiencias de educación conjunta de niños inteligentes, mediocres y retrasados. Se pide al Ministerio de Educación la promoción de tales experiencias, así como una reglamentación preceptiva para las instituciones docentes privadas, en el sentido de la aceptación de los retrasados en la escolaridad ordinaria" (p. 16). La autora acusa a la institución escolar, que debiera integrar, de fundamentar una actitud reprobatoria y discriminativa amparándose en la teoría determinista de las aptitudes. También sostiene que cabe pensar que un alto porcentaje podrían evitarse 0 atenuarse. Propone incidir en la orientación preventiva, la toma de conciencia de las familias sobre situaciones injustas, la evaluación critica, por parte de las familias, de los recursos institucionales y su funcionamiento y el análisis de los factores sociales que pueden haber provocado la deficiencia en su familia y la respuesta que la sociedad da a su problema (p. 24).

${ }^{89}$ Un buen trabajo de época sobre la influencia de los tebeos en la formación y la personalidad infantil, inserto en una publicación expresamente destinada al magisterio, es el de Jorge B. Rioboo, Luis Conde y Vicente L. Botín, "Los tebeos", Vida Escolar 155 (1974), 50-81.
} 
réndum "daba estabilidad a la sociedad y que Franco era una persona providencial en la historia de España" ${ }^{90}$ En la misma órbita religiosa encontramos su faceta como Profesor Especial de Formación Religiosa del Instituto Laboral de Tarazona entre 1953 y 1957. Fruto de esta primera etapa, hasta 1972 sus obras van a ser de carácter religioso, en concreto sobre la vocación sacerdotal. De esta temática no tarda en pasar a la salud mental infantil y escolar con su participación en los CESM en los años 1974-1975, incluso con una intervención en Televisión Española sobre premios y castigos. A partir de la década de los ochenta se dedica a estudios psicosociales en el ámbito del turismo y culmina este periplo como Jefe de la Sección "Formaciones Básicas de Personal de Salud de la Consejería de Salud de la Comunidad Autónoma de Madrid", y participando en el reconocimiento de la Psicología Clínica como especialidad sanitaria. El BOE nos confirma que en 1977 ingresa en la Escala de Facultativos y Especialistas "en puestos de Psicólogos", y en turno restringido, previa demostración, aunque no se dispusiera del título oficial, de que se había estado ejerciendo como tal.

Respecto a su aportación en los CESM y tras explorar tres de ellos (Sanciones escolares y salud mental, La violencia, amenaza para la salud psíquica de la escuela y Educación integral y salud mental), percibimos en el autor un decidido posicionamiento hacia el enfoque propio del análisis institucional, ${ }^{91}$ de muy escasa presencia en la pedagogía española de la época, reducido a una mera exposición teórica en algunos espacios académicos de la pedagogía y a una circulación "semiclandestina" en los no académicos. Este enfoque ubicaba la escuela —al igual que la organización hospitalaria o manicomial— en el juego de unas dinámicas de poder en las que se articulan y desarrollan conflictos y contradicciones encarnados en unas determinadas prácticas, con claras repercusiones sobre la salud mental de la infancia escolarizada. En su planteamiento pedagógico-terapéutico, dirigido a neutralizar y descomponer el conjunto de mecanismos que desencadenaban patologías escolares e inadaptación escolar, vemos la influencia del movimiento Freinet. Garde lo nombra y lo cita, a pesar de que en España se mantenía recluido en pequeños círculos de maestros, si bien con capacidad organizar encuentros nacionales ya desde finales de los sesenta.

En los textos señalados, particularmente en el segundo (La violencia, amenaza para la salud psíquica de la escuela), Garde refiere la violencia estructural constitutiva de la escuela, que no se reduce a las sanciones escolares propiamente dichas, sino que permea su proceder cotidiano. Una violencia que se manifiesta en (y se nutre de): la relación antidialógica que articula la acción maestro/alumno -en una clara referencia conceptual al pedagogo Paulo Freire-; las condiciones de encuadramiento y masificación del alumnado en la escuela; y la naturaleza de una tarea - la escolar - que niega a la persona el estatus de sujeto activo y participante, robotizándolo o gestando patológicas reacciones explosivas. E incluso de unas enseñanzas disciplinares que, como ocurre con la Historia, hacen

\footnotetext{
${ }^{90}$ Pedro Mendoza, Mi memoria histórica (1948-1988) (Madrid: Bubok Publishing, 2009), 68.

${ }^{91}$ Atendiendo a las influencias de su compañero sacerdote de publicaciones, Manuel Alemán Álamo, puede que los vientos de la Teología de la Liberación y el socialismo cristiano de Freire formaran parte de esta simbiosis.
} 
una sanción positiva de la violencia, entendida como justa y lícita cuando se apela a instituciones como el Estado, la tradición y la conciencia, desde "el supuesto de que la ley, el orden y los cauces legales son principios absolutos, de origen teocrático, que se defienden por la violencia". ${ }^{92}$ Una violencia encarnada también en los aspectos relacionales de la vida escolar, favorecedores de sentimientos de inferioridad o de superioridad en los sujetos. En tales estructuras caben perniciosas relaciones profesor/alumno, rechazables tanto cuando conforman profesores extremadamente blandos como cuando se manifiestan en alguna forma de violencia, sea física, moral o intelectual, sobre sus alumnos, quienes, finalmente, acabarán introyectándola. Y, en fin, una violencia derivada de problemáticas sociales generadoras de una frustración creciente entre niños y jóvenes a causa del contraste entre los modelos ideales de vida y de trabajo difundidos por los mass media y las (sus) condiciones concretas de existencia. Una violencia manifiesta también en las diferentes oportunidades brindadas a cada alumno, víctima de desigualdades sociales que no neutraliza el régimen de becas, manteniéndose el clasismo (aunque hayan desaparecido las diferentes puertas -para ricos y para pobres - que tenían muchos colegios católicos), recluyéndose en la escuela estatal los "desheredados de la fortuna o del saber" ${ }^{93} \mathrm{~A}$ la universidad, afirma, solo accede un escasísimo porcentaje de hijos de trabajadores. Situaciones, en conjunto, con un innegable efecto desmoralizador entre profesores y alumnos.

En el Cuaderno titulado Educación integral y salud mental, Garde avanza una propuesta a partir de la ecuación que se sostiene en el título. Para la perspectiva psicopedagógica en que se sitúa (hay otras: la médica, la sociológica), fundamentada en los conceptos de crecimiento, maduración y desarrollo de la personalidad más que en la presencia o ausencia de enfermedades, promover salud implica educar integralmente a individuos desde un conjunto de valores múltiples, no estáticos y universales sino, frecuentemente, con componentes antinómicos. ${ }^{94}$ Unos valores que han de ser precisados y que procede que la escuela los adopte en su seno tanto para modelar el desarrollo y la maduración del alumnado de hoy, como para conectar con él. Los valores que refiere como propios de la juventud "actual", que rechaza el inmovilismo "tradicional", son los de la civilización contemporánea, los propios de un humanismo ya no filosófico o contemplativo sino técnico, al igual que nuestra civilización. Los principios de procedimiento que se hacen emanar de los considerados más significativos conforman una guía de la práctica escolar mentalmente saludable, en la que reconocemos tanto el modelo Freinet, con quien comparte enunciados básicos, como, sobre todo, los planteamientos de la pedagogía no directiva de Carl Ro-

\footnotetext{
${ }_{92}$ Rafael Garde Enciso, La violencia, amenaza para la salud psíquica en la escuela (Madrid: Dirección General de Sanidad, 1975), 12.

${ }_{93}$ Ibídem, 22.

${ }^{94}$ Hemos referido el papel crucial de la formación en valores, como estructura sobre la que apoyar la adquisición de los compartimentos higiénico saludables, en Inma Hurtado García y Aida Terrón Bañuelos, "La educación sexual durante la transición: Modelando discursos y modulando voces", en Genealogías de la reforma sanitaria en España, 155-191. El "sentimiento de la dignidad personal" fue objeto de una ponencia especial en la Conferencia de Hamburgo a la que nos hemos referido.
} 
gers. ${ }^{95}$ Esos valores, estimados por los jóvenes en cuanto que son propios y específicos de su tiempo - la acción, la eficacia, el trabajo en equipo, el sentido del futuro, el diálogo y la simetría entre mujeres y hombres, entre otros-, habrían de fundamentar las buenas prácticas escolares. Su bondad reside en que promueven la toma de conciencia del educando, el compromiso con su vida, la autorresponsabilidad. Prácticas en las que el profesor se coloca en la condición de catalizador o reactivo, situándose de cara a la verdadera necesidad del educando que dialoga, la cual no siempre queda expresada por sus palabras; que se interesa, más que por los hechos del educando, por su punto de vista (por su persona); que escucha más que habla; y que evita crear relaciones de dependencia. Buscando un símil inequívoco, ${ }^{96}$ compara ese papel de "eterno auxiliar" propio del educador — que impide al educando organizar sus energías partiendo de sus necesidades y problemas - con los pueblos en vías de desarrollo, para los que la ayuda recibida conduce, muchas veces, a prolongar su dependencia y subdesarrollo.

La decidida muestra de adhesión a la pedagogía institucional que manifiestan estos textos no deja de ser bastante marginal, según hemos dicho. Constituye una muestra más de la disputa por la hegemonía entre los diferentes discursos que operaban a lo largo del tardofranquismo en los diferentes ámbitos profesionales - también en psicología, psiquiatría o pedagogía-, que marcaron la dinámica de la Transición hasta su estabilización tras la Democracia. En ese momento se procedería a acometer, como se sabe, potentes ordenamientos estabilizadores, particularmente en los ámbitos que nos ocupan, la sanidad y la educación, a cuyo objetivo se desplegó una profusa promulgación de leyes básicas, ordenamientos diversos y regulación de Servicios.

\section{Conclusiones}

El camino transitado nos devuelve algunas constantes en los discursos que nos permiten identificar el lugar de la salud mental en la educación, un lugar central, imprescindible para afrontar los cambios sociales, apoyado en unos saberes y profesionales específicos que van a poner en la técnica todas sus esperanzas. La Conferencia de París y el texto de Wall sitúan en primer plano la cuestión de la salud mental en la escuela, a la vez que evidencian cómo la psicología piensa la educación y cómo se proyecta la incursión de los psicólogos de la educación europeos para marcar su campo científico. Una de las muestras es su interés por vincularse a la escuela y a la población normal, cuya salud mental —edificada en el acogimiento, el afecto, el respeto individualidad y el ritmo de aprendizaje- depende de que la escuela y la familia queden bajo su amparo profesional.

La salud mental escolar se presenta como un ámbito interdisciplinar necesitado de otras ciencias, en el que tanto los médicos como los docentes (pero fundamentalmente

\footnotetext{
${ }^{95}$ También denominada "pedagogía centrada en el cliente" por extensión (pertinente, dado el isomorfismo que Rogers encontraba entre terapia y educación) de la expresión "terapia centrada en el cliente" o en la persona. Según Piaton, al final de su vida Freinet veía esta pedagogía interesante y próxima, como también las pedagogías institucionales y "de grupo". George Piaton, "Freinet y la Escuela Nueva", Revista de Educación 242 (1976): 43-50.

${ }^{96}$ Garde Enciso, Educación Integral y Salud mental, 23.
} 
los primeros) irán perdiendo centralidad en su atribución para definir y actuar sobre la realidad escolar en favor de la psicología y el psicoanálisis. En la disputa entre campos científicos que quieren hacerse un espacio académico y profesional, destaca la psicología, particularmente, si bien la pedagogía buscará seguir el mismo recorrido: las Ciencias de la Educación buscaban su espacio y su estatuto. Todavía los médicos pueden intervenir desde la educación sanitaria escolar, pero van a ir perdiendo doctrina e influencia conforme la sanidad se va organizando en todas las esferas y llega a la población, restándose protagonismo a algunas cuestiones de higiene de las que los médicos se ocupaban.

Los maestros, pese a muchas apariencias en sentido contrario, están siendo desposeídos de su autonomía, de su capacidad de pensar y en consecuencia actuar sobre la realidad educativa en la que intervienen, tal como denunciaban Freinet y sus camaradas. Lo cual no obsta para que se mantenga un discurso generalizado y extendido sobre la relevancia "atmosférica" del maestro responsable del "clima de la clase", haciendo pivotar sobre él la salud mental escolar a base de regular emociones y modular relaciones. Algunos acentúan la dimensión de esa relación desde la perspectiva psicoanalítica (Lunay, Ajuriaguerra) o gremial, pero en general, todos perciben ahí el punto central, en esa relación maestro-alumnos-sistema de la clase.

En España no hay información o trabajos mínimamente consistentes sobre la salud mental escolar antes de 1975, cuando se publican los CESM. Tampoco parece que, al margen de los artículos y autores que hemos mencionado, fuera un tema de interés. Sin embargo, se puede constatar la diversidad de discursos manejados en relación con la salud mental de los escolares en algunos números de los CESM (recuérdese, dirigidos al ámbito psico-sanitario); en las propuestas de la educación sanitaria escolar modelo OMS en su versión española, que recogía por esos mismos años la Enciclopedia de didáctica aplicada dirigida por Maíllo y destinada, en este caso, al ámbito académico de la pedagogía y, de modo expreso, a la formación de maestros; o la propuesta de principios sobre la higiene mental de los escolares enunciados por Prandi frente a las propuestas de Garde Enciso. Lo que nos lleva a preguntarnos ¿hubo una salud mental escolar como parte del núcleo Educación sanitaria escolar o Educación para la salud, tal como pudieron enunciarlo Turner, OMS y otros? No parece que la hubiera. Según lo observado en estas décadas y ateniéndose a lo que sucedió en las posteriores, todo parece indicar que quedó subsumida en la Orientación Escolar, para la población normal, y en la Pedagogía Terapéutica, en sus distintas denominaciones (pedagogía de anormales, pedagogía para subnormales, etc.), para el resto. Y si bien en los proyectos de trabajo y/o de investigación sobre educación para la salud que se acometieron en España tras 1975, apoyados por las administraciones educativa y sanitaria, aparece el subnúcleo salud mental —a la par que otros: nutrición, educación ambiental, educación sexual-, es un poco la fuerza de la inercia. La salud mental escolar quedará en manos de centros especializados de salud mental infantil, gabinetes de orientación, psicopedagógicos, orientadores escolares, etc. con un carácter muy técnico, individualizador, sin que pedagógicamente llegase a tomar impulso. 


\section{Bibliografía}

Ajuriaguerra, Julián de. Manual de Psiquiatría infantil. Barcelona: Toray Masson, 1973.

Alegre-Agís, Elisa, Josep Barceló-Prats y Josep Maria Comelles. "La confusión de los psiquiatras. Las narrativas en torno a la crisis del custodialismo durante el tardofranquismo". Revista de Historia de la Psicología 39/1 (2018): 31-39.

BIE-UNESCO. Les psychologues scolaires, n¹04. Ginebra y París: BIE-UNESCO, 1948.

Carballo, Rof. "La higiene mental del maestro". Vida Escolar 26 (1961): 35.

Freinet, Célestin. "Pour une année international de l'éducation". L'Éducateur 3 (1958): 8-10.

Freinet, Célestin. "Un congrès qui marque d'une façon décisive la grande maturité de notre mouvement de l'Ecole Moderne". L'Éducateur 19 (1958): 1-7.

Freinet, Célestin. "Les soucis d'Éducation doivent s întegrer aux travaux de l'Année internationale de la santé mentale". L'Éducateur 9 (1959), 27-29.

Freinet, Célestin. "La pédagogie Freinet de l'Ecole Moderne et la santé mentale des enfants et des maitres (prévention y cure)". L'Éducateur 17 (1959).

Freinet, Célestin. La santé mentale des enfants. Cannes, Francia: Editions de l'école moderne française, 1961.

Freinet, Célestin. El equilibrio mental de niño. Barcelona: Laia, 1978.

Gutiérrez, Fernando. Los españoles y la educación sexual. Barcelona: Fontanella, 1974.

Hurtado García, Inma y Aida Terrón Bañuelos, "La educación sexual durante la transición: Modelando discursos y modulando voces". En Genealogías de la reforma sanitaria en España, editado por José Martínez Pérez y Enrique Perdiguero Gil, 155-191. Madrid, España: Catarata, 2020.

Irisarri, Fabiola. Psiquiatría crítica en España en la década de los 70, Tesis doctoral, Universidad Complutense de Madrid, 2018.

Launay, Clément. La higiene mental del escolar. Barcelona: Luís Miracle, 1968.

Maíllo, Adolfo. "El Servicio social escolar". En Organización y supervisión de escuelas, editado por Ministerio de Educación Nacional, 137-152. Madrid: CEDODEP, 1966.

Maílo, Adolfo (ed.). Enciclopedia de didáctica aplicada. Barcelona: Labor, 1974.

Martínez-Hernáez, Ángel y Martín Correa-Urquiza. "Un saber menos dado: Nuevos posicionamientos en el campo de la salud mental colectiva". Salud Colectiva 13 (2017): 267-278.

Mauco, Georges. Psychanalyse et éducation. París: Aubier-Montaigne, 1968. Trad. cast. Psicoanálisis y educación. Buenos Aires: Carlos Lohlé, 1969.

Mendoza, Pedro. Mi memoria histórica (1948-1988). Madrid: Bubok Publishing, 2009. 
Ministerio de Educación Nacional. Orientaciones Pedagógicas para directores escolares. Madrid: CEDODEP, 1965.

Novella Gaya, Enric J. "La psiquiatría franquista y la educación para la salud mental". En Educación, comunicación y salud, coordinado por Josep M. Comelles y Enrique Perdiguero-Gil, 81-103. Tarragona: Publicacions URV, 2017.

Novella Gaya, Enric J. "Los límites de la tecnocracia: La modernización autoritaria de la asistencia psiquiátrica en la España del segundo franquismo". Dynamis: Acta Hispanica Ad Medicinae Scientiarumque Historiam Illustrandam 39/1 (2019): 73-97.

Piaget, Jean. Le droit à l'éducation dans le monde actual, Colecc. Droites de I'homme, 1. París: UNESCO, 1949.

Piaton, George. "Freinet y la Escuela Nueva”. Revista de Educación 242 (1976): 43-50.

Prandi, Francesc. "Fisiología e higiene y educación sanitaria". En Enciclopedia de didáctica aplicada, editado por Adolfo Maíllo, 611. Barcelona: Labor, 1974

Rioboo, Jorge B., Luis Conde y Vicente L. Botín. "Los tebeos", Vida Escolar 155, (1974): 50-81.

Rujas Martínez-Novillo, Javier. "La construcción del "fracaso escolar". España. Génesis y cristalización de un problema social”. Papers 102/3 (2017): 477-507.

Serigó Segarra, Adolfo. Medicina e higiene escolar. Introducción a la Medicina Pedagógica. Madrid: Cultura Clásica y Moderna, 1958.

Serigó Segarra, Adolfo. Medicina preventiva y Social. León: Institución Fray Bernardino de Sahagún. Everest, 1972.

Simón Lorda, David. "El Patronato Nacional de Asistencia Psiquiátrica (PANAP) y sus contradicciones: entre el enfoque psicosocial y el modelo manicomial". En Psiquiatría y antipsiquiatría en el segundo franquismo y la Transición, editado por Rafael Huertas, 15-46. Madrid, España: Catarata, 2017.

Simón Lorda, David. "Atención psiquiátrica. salud mental y salud pública en el tardofranquismo". En Genealogías de la reforma sanitaria en España, editado por José Martínez Pérez y Enrique Perdiguero Gil, 127-154. Madrid, España: Catarata, 2020.

Terrón Bañuelos, Aida. "La educación sanitaria escolar, una propuesta importada para la escuela española del desarrollismo". Archivos Analíticos de Políticas Educativas 23/1 (2015).

Terrón, Aida. "La educación sanitaria escolar, matriz generadora de las materias transversales del currículum (1960-1980)". En Modernización educativa y socialización política. Contenidos curriculares y manuales escolares en España durante el tardofranquismo y la transición democrática, coordinador Manuel Ferraz, 280-305. Madrid: Morata, 2019. 
The British Psychological Society, Commitee of Professional Psychologists (Mental Health). "Memorandum on the schools' psychological services in Europe". En Conference on Education and the Mental Health of Children in Europe. París: UNESCO, 1952.

UNESCO. El derecho a la educación. París: UNESCO, 1952.

UNESCO. Health education, sex education and education for home and family life (Report on an Expert Meeting). Hamburgo: UNESCO Institute for Education, 1965. La versión castellana, Educación para la salud, el sexo y la vida familiar. Buenos Aires: Paidós, 1971.

VVAA. Ciencias de la Educación. Contestaciones al cuestionario oficial de las oposiciones a ingreso en el magisterio nacional (convocatoria 1970). Madrid: Escuela Española, 1970.

Wall, Williams Douglas. La Psycologie au service de l'ecole. París: Bourrelier, 1958.

Wall, Williams Douglas. Educación y Salud Mental. Madrid: Aguilar, 1963 (edición original 1955).

Zazzo, René. "Report on school Psychology". En Conference on Education and the Mental Health of Children in Europe. París: UNESCO, 1952. 